\title{
Das korinthische Herrenmahl im Schnittpunkt hellenistisch-römischer Mahlpraxis und paulinischer Theologia Crucis (1Kor 11,17-34)
}

\author{
von Peter Lampe \\ (3401 Brook Rd., Richmond VA 23227, USA)
}

Vor dem Hintergrund hellenistisch-römischer Mahlpraxeis wird vorliegender Aufsatz eine gegenüber bisherigen Rekonstruktionen neue Sicht der korinthischen Situation vorschlagen. In einem II. Teil werden Paulus' praktische Direktiven angesichts dieser Situation, im III. Teil die theologische Grundlegung dieser praktischen Empfehlungen beleuchtet werden.

\section{Analyse der korinthischen Situation}

1. Rahmenbedingungen

Die Korinther kommen zusammen, um das eucharistische Herren-

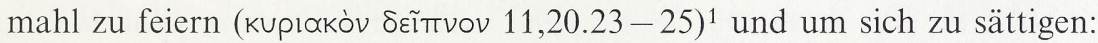
Einige werden übermäßig satt; andere bleiben hungrig, was Paulus entrüstet $(11,21 b)$. Die Verbindung von Eucharistie und Sättigungsmahl ist mithin für Korinth gesichert ${ }^{2}$, auch wenn nicht auf Anhieb klar wird, wie beide verknüpft sind.

Die Paradosis von 1Kor 11,23-25 stellt als Ablauf vor Augen: Brotwort - eine Mahlzeit - Kelchwort ${ }^{3}$. Es erscheint unwahrscheinlich,

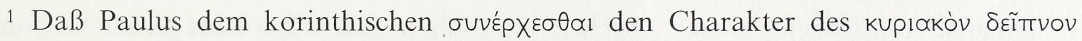
abspricht $(11,20)$, schließt nicht aus, sondern ein, daß die Korinther den Anspruch erheben, bei ihrem Versammeln das Herrenmahl zu begehen: Paulus spricht ihnen $a b$, was sie beanspruchen. Deshalb kann er sie auf die eucharistische Paradosis $(11,23-25)$ hin ansprechen.

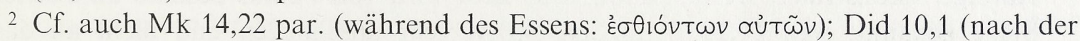
Sättigung). Zur Forschungsgeschichte H.-J. Klauck, Herrenmahl und hellenistischer Kult. Eine religionsgeschichtliche Untersuchung zum ersten Korintherbrief, NTA N.F. $15,1982,294 \mathrm{f}$.

3 Cf. das jüdische tägliche Mahl, das von einem Eingangsgebet (Lobspruch beim Brotbrechen) und einem Schlußdankgebet gerahmt wurde. Beim jüdischen Festmahl kam Wein hinzu; jeder Becher, besonders der Schlußbecher, wurde von einem Segensspruch begleitet. So rahmten Brot und Wein jede jüdische Festmahlzeit. 
daß Paulus diese Paradosis zitierte, wenn die Korinther nicht einen entsprechenden Ablauf befolgten ${ }^{4}$. Paulus gab den Korinthern schon bei

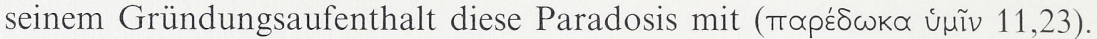
Sie dient in der Argumentation des Abschnittes als gemeinsame Basis, von der her Paulus argumentiert und die Korinther zu überzeugen sucht ${ }^{5}$. Da Paulus in 11,23a versichert, so und nicht anders habe er die Paradosis empfangen, erwartet er stillschweigend, daß die Korinther sich an ihren Wortlaut halten. Würden sie einen anderen Ablauf praktizieren, so wäre das feierliche Zitat der Paradosis nur dazu angetan, die Korinther zu verwirren und die »Unordnung« bei ihren Gottesdiensten (14,33) zu vergrößern. Zur Annahme eines von der Formel abweichenden Ablaufs in Korinth zwingt nichts.

Sakramentale Mahlzeiten des Frühjudentums lehnten sich im Ablauf an das festliche und tägliche jüdische Mahl an. Siehe Klauck, Herrenmahl, 66 f.91.203f.

${ }^{4}$ Cf. ausführlich G. Theißen, Soziale Integration und sakramentales Handeln. Eine Analyse von 1Cor. XI 17-34, NT 16, 1974, 187 f.; gegen z. B. P. Neuenzeit, Das Herrenmahl. Studien zur paulinischen Eucharistieauffassung, StANT 1, 1960, $71 \mathrm{f}$. (die dortigen Argumente werden von Theißen schlüssig widerlegt), G. Bornkamm, Herrenmahl und Kirche bei Paulus, in: ders, Studien zu Antike und Urchristentum, Ges. Aufs. 2, BEvTh 28, 1963, 155, Klauck, Herrenmahl, 295, und P. Stuhlmacher, Jesus von Nazareth - Christus des Glaubens, Stuttgart 1988, 83. - Klauck beruft sich für eine angeblich korinthische Abfolge von >Mahl - Brot/Kelch auf Mk 14,22, wo aber ein Partizip Präsens steht: »während des Essens«, nicht danach. Zweitens beobachtet Klauck: Paulus rechnet nicht damit, daß die zu spät kommenden Korinther auch das Brotwort versäumten. So richtig das ist, es läßt sich nicht als Grund gegen einen von den Korinthern befolgten Ablauf von >Brotwort - eine Mahlzeit - Kelchwort $<$ verwenden, wie sich unten bei der Unterscheidung zwischen mensae primae und secundae erweisen wird. - Stuhlmacher rekonstruiert eine Abfolge von (1) Lob und Dank über erst Wein und dann Brot, (2) Sättigungsmahl, (3) Austeilen von erst Brot und dann Wein. Er lehnt sich dabei an Did 9,1-5 an. Aber a) schon der Vergleich von 1Kor 11,23-25 mit Mk 14,22-25 lehrt, daß es die »Konstanz« liturgischer Tradition (103 Anm. 20), die das Heranziehen der Didache rechtfertigte, so nicht gegeben hat. Stuhlmacher selber lehrt gerade Diskontinuität liturgischer Praxis, wenn er behauptet, daß das $\mu \varepsilon \tau \dot{\alpha}$ tò $\delta \varepsilon ı ा \tau \tilde{\eta} \sigma \propto l$ des Kelchwortes $(11,23-25)$ in Korinth nicht mehr praktiziert wurde. b) Zweifelhaft bleibt, ob aus der Reihenfolge von Kelch und Brot in 1Kor 10,16 eine liturgische Abfolge rekonstruiert werden kann: Das Brot wird von Paulus deshalb an zweiter Stelle genannt, weil 10,17ff. an den Brotverzehr anschließen und nicht an das Trinken. c) Wurde das Sättigungsmahl ohne Brot - für ein antikes Mahl undenkbar - oder mit einem anderen Brot als dem eucharistischen abgehalten? Lagen zwei verschiedene Brote, ein profanes und ein eucharistisches, auf dem Tisch? d) Das Sättigungsmahl vom Austeilen des Brotes zu trennen, findet in den frühen Quellen keinen Anhalt. Stuhlmacher selber (86) notiert, daß erst seit Justin GemeindeSättigungsmahl und Herrenmahlsfeier getrennt voneinander gehalten wurden.

${ }^{5}$ Cf. dgl. z. B. $15,3-5$. 
Das heißt, in Korinth wird zuerst das Brotwort als Eröffnungssegen gesprochen. Dann findet ein Mahl statt. Nach demselben $(11,25)$ wird der Weinkelch gesegnet, die Teilnehmer trinken.

Das korinthische Versammeln zu Sättigungsmahl und Eucharistie findet am Abend statt. Für den Abend spricht nicht nur das $\dot{\varepsilon} v$ Tñ

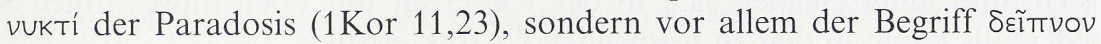
(11,20 f.25), der in der zeitgenössischen Umwelt die abendliche Hauptmahlzeit des Tages benennt ${ }^{6}$.

Der Mißstand, der sich in Korinth eingestellt hat, besteht darin, daß während des Mahles zwischen Brot- und Kelchwort nicht genügend Speisen auf den Tischen stehen, die alle satt machen könnten. Einige in der Gemeinde bleiben hungrig $(11,21)$. Paulus ist entrüstet, woraus folgt, daß das Mahl zwischen Brot- und Kelchwort zumindest im Anfang der korinthischen Gemeindegeschichte als ein nicht nur einige, sondern alle Gemeindeglieder sättigendes Mahl konzipiert war. Der Mißstand wird in Abschnitt I.4 zu analysieren sein.

Wer nach Umwelt-Hintergründen für das Fehlverhalten der Korinther sucht, wird nach solchen ausschauen, die für möglichst viele Korinther zutreffen: Wir werden methodisch - noch mehr als in der bisherigen Forschung - bei den alltäglichen Gastmählern der Umwelt einsetzen und nicht gleich auf sakrale Mahlzeiten wie Opfer- oder Mysterienmähler zusteuern. Aus drei Gründen: a) Das alltägliche Gastmahl kann bei allen Korinthern als bekannt vorausgesetzt werden. Lassen sich plausible Gründe für das korinthische Fehlverhalten bereits in der alltäglichen paganen Mahlpraxis finden, so erübrigt sich das Illuminieren von z. B. Mysterienpraxeis, die wohl einigen, aber kaum allen Korinthern vertraut waren. b) Die sakralen Mahlzeiten der Umwelt lehnten sich in ihrem Ablauf in aller Regel an die alltäglichen Mahlzeiten an an $^{7}$ Bereits diese Beobachtung legt nahe, daß auch die Korinther in ihrem Sakramentsvollzug von der alltäglichen Mahlpraxis beeinflußt waren. c) Um so mehr gilt dies, als der eucharistische Ritus in Korinth mit einem abendlichen Sättigungsmahl verbunden war.

${ }^{6}$ Cf. z. B. W. Bauer, Griechisch-deutsches Wörterbuch, hg. v. K. u. B. Aland, Berlin 61988, 346; D. E. Smith, Social Obligation in the Context of Communal Meals. A Study of the Christian Meal in 1 Corinthians in Comparison with Graeco-Roman Communal Meals, Diss.theol. masch. Harvard 1980, 6.24. - Für ein Versammeln am Abend oder Vorabend des Sonntags spricht 1Kor 16,2 im Verein mit Act 20,7; Apk 1,10; IgnMagn 9,1; Did 14,1; Barn 15,9.

7 Dies hat z. B. Smith (Obligation, 90.97-99.136.145) schön gezeigt, ebenso H. C. Youtie, The Kline of Sarapis, HThR 41, 1948, 9-29. Auch die jüdische PassahLiturgie verrät noch den Hintergrund normaler griechisch-römischer Mahlpraxis: G. J. Bahr, The Seder of Passover and the Eucharistic Words, NT 12, 1970, 181 202; S. Stein, The Influence of Symposia Literature on the Literary Form of the Pesah Haggadah, JJS 8, 1957, 13-44; Smith, Obligation, 178 f., und cf. o. Anm. 3. 
2. Erste Parallelen zwischen christlichem Abendmahl und abendlicher Hauptmahlzeit in der Umwelt

In der Umwelt läuft die abendliche Hauptmahlzeit, wird sie in Geselligkeit eingenommen, nach folgendem Muster ab. Griechische und römische Sitte unterscheiden sich in der Kaiserzeit nur noch unwesentlich ${ }^{8}$, jedenfalls kaum in den zu nennenden Charakteristika.

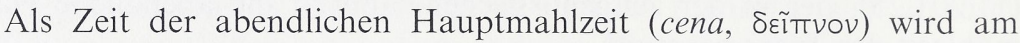
häufigsten die neunte Stunde genannt ${ }^{9}$. Sehr Beschäftigte essen eine Stunde später (Martial 7,51,11). Vorher wird oft zur achten Stunde ein Bad in den Thermen genommen ${ }^{10}$. - In der Kaiserzeit wird nicht nur zum Nachtisch, sondern während der ganzen Mahlzeit getrunken; schon zu Beginn wird mit Honig angemachter Wein gereicht ${ }^{11}$. Die angetrunkenen Eucharistieteilnehmer in Korinth (1Kor 11,21) ordnen sich hier ein. Nach der Cena wird oft bis zum Schlafengehen in geselliger Runde verweilt ${ }^{12}$, oft genug an den vor den Speisesofas aufgestellten secundae

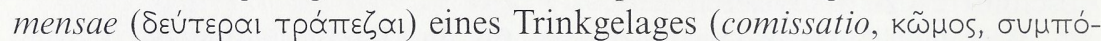
$\sigma(O v)^{13}$.

Religiöses Zeremoniell ist mit diesem Tafeln auch im alltäglichen paganen Bereich verbunden. Die Cena beginnt mit einer Götter-Akklamation ${ }^{14}$. In der Pause zwischen primae und secundae mensae werden die Laren und die Genien des Hausherrn und des Kaisers angerufen und ein Opfer gebracht ${ }^{15}$. Haben die Speisen und das Trinken der comissatio sich

8 Cf. z. B. die Gegenüberstellung bei Smith, Obligation, 5 ff.24ff. Zur folgenden Darstellung cf. auch A. Mau, Art. Cena, PRE 3/2, 1899, 1895-1897; ders., Art. Convivium, PRE 4/1, 1900, 1201-1208; ders., Art. Comissatio, PRE 4/1, 1900, 610-619; A. Hug, Art. Symposion, PRE II 4/1, 1931, 1266-1270.

9 Cic., Ad Fam 9,26,1; Hor., Ep 1,7,71; Martial 4,8,6; cf. 10,48; 11,52; achte bzw. neunte Stunde: P.Oxy. 110; 2678 (3. Jh. n. Chr.); 2791 (2. Jh. n. Chr.).

10 Martial 11,52; 10,48; Plato, Symp 174 A.

11 Petron 34; Hor., Sat 2,8,14-17; 2,4,24-26; Athenaios, Deipn 2,58 B-C; Plut., QuConv 8,9 (734 A).

12 Z. B. Plin., Ep 3,1,9; cf. 3,5,13.

$13 \mathrm{Zu}$ der mit den secundae mensae beginnenden comissatio s. Mau, Art. Cena (s. Anm. 8) 1897; ders., Art. Comissatio (s. Anm. 8); griechische und römische comissatioSitte unterscheiden sich nicht wesentlich. Ob die secundae mensae mit ihren Desserts

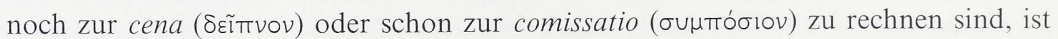
eine terminologische Frage, die nichts an dem Ablauf der Ereignisse ändert. In der

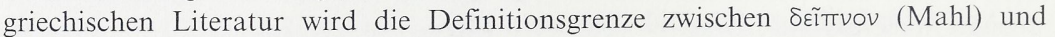

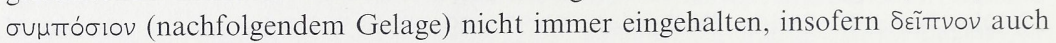

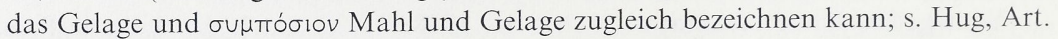
Symposion (s. Anm. 8) 1267.

${ }_{14}$ Quint., Decl 301 (Ritter, 187).

15 Hor., Od 4,5,31f. (vor den secundae mensae); Servius, Aen 1,730; Petron 60 (vor dem Nachtisch Huldigung für Kaiser und Laren); Cass. Dio 51,19,7 (Dekret bereits 
eine Weile abgewechselt ${ }^{16}$, beendet ein Trunk ungemischten Weines, der dem ở $\gamma \propto \theta \dot{s} s \delta a i ́ \mu \omega v$ dargebracht wird, die Desserts der secundae mensae. Die Eßtische werden abgeräumt. Das eigentliche Trinkgelage beginnt damit, daß im Krater Wein mit Wasser gemischt und ein Trankopfer ( $\sigma \pi \circ \delta \delta \eta ்$ ) dargebracht wird ${ }^{17}$; die Versammelten singen - zuweilen mit Flötenbegleitung - einen Paian dazu ${ }^{18}$. Bei jedem neuen Krater wird die

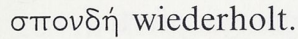

Zusammengenommen ergibt sich folgendes Muster:

- Götterakklamation

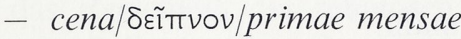

- Pause - Übergang: mit Opfer verbundenes Anrufen der Laren und Genien des Hausherrn und des Kaisers

- secundae mensae/ Desserts und Trinken

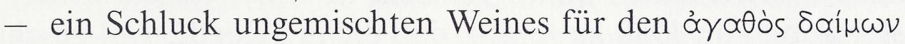

- Abräumen der Eßtische

- Mischen des ersten Kraters, Trankopfer, Gesang

- Trinken, Konversation

- Mischen des zweiten Kraters, Trankopfer

- Trinken, Konversation, etc.

Angesichts dieses Befundes ist für die heidenchristlichen Korinther das religiöse Element bei der abendlichen christlichen Mahlzeit nichts Neues. Es bieten sich ihnen sogar Vergleichspunkte im Detail.

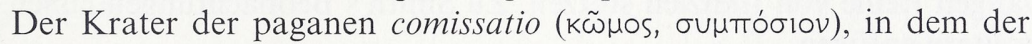
Wein gemischt wird, bevor Sklaven ihn in die Schalen der Versammelten gießen ${ }^{19}$, kann den Korinthern als mit dem einen тооти́pıov des Herrenmahls $(1$ Kor 10,16) vergleichbar erscheinen. Wird doch nicht nur der Herrenmahlskelch liturgisch gesegnet (1Kor 10,16), sondern auch an der paganen Tafel jedes neue Weinmischen im Krater mit Trankopferzeremo-

des Jahres 30 v. Chr.: auch beim privaten Mahl hat jeder für den Augustus ein Trankopfer darzubringen); W. Henzen (ed.), Acta Fratrum Arvalium, Berlin 1874, $42 \mathrm{f} .15$ (Opfer zwischen primae und secundae mensae).

16 Cf. z. B. Athen., Deipn 4,129.

17 Die Belege zum Trankopfer bei Mau, Art. Comissatio (s. Anm. 8) 611. Libation und Gesang gehören zusammen: Plato, Symp 176 A; Xen., Symp 2,1 (nach dem Abräumen der Tische). - Plato und Xenophon beeinflußten aufgrund ihrer Popularität maßgeblich die Mahlpraxeis der Kaiserzeit. Cf. Smith, Obligation (s. Anm. 6) 4, und z. B. Plutarchs (QuConv 7,7 [710 BC]) Aufnahme von Plato, Symp 176 E.

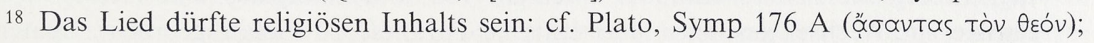
Plut., QuConv 7,8 (713 A); 1,1 (615 B).

19 Die Belege dazu bei Mau, Comissatio (s. Anm. 8) 612. 
niell und religiösem Gesang begleitet. Obendrein bedeutet nicht nur die

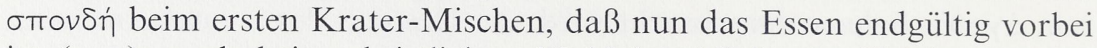
ist (s. o.), auch beim christlichen Mahl beschließt der Kelchsegen das Essen, wie die Paradosis 1 Kor 11,23-25 zeigt.

Dem Brotwort als Eröffnungssegen entsprechen beim paganen Mahl die genannten Akklamationen vor der cena einerseits und vor den secundae mensae andererseits; vor den secundae mensae wird sogar geopfert.

\section{Das korinthische Abendprogramm nach dem sakramentalen Herrenmahl}

Mit der Abfolge Brotwort - Mahl - Kelchwort ist nicht das ganze korinthische Abendprogramm wiedergegeben. Was findet davor, was danach statt?

Zunächst das Danach. Smith versucht in seiner ungedruckten Harvard-Dissertation von 1980 zu zeigen, daß die in 1 Kor $12+14$ geschilderten Vorgänge - prophetisches Reden zur Erbauung und Ermahnung $(14,3)$, Worte der Offenbarung, der Erkenntnis, der Weisheit, der Weissagung, der Lehre $(14,6.26 ; 12,8)$, Singen (14,15 f.26), Zungenrede und ihre Auslegung $(14,5.26)$ - nach dem Essen und nach dem Kelchsegen während eines sich hinziehenden christlichen Symposions stattgefunden haben könnten ${ }^{20}$. Beim Umwelt-Symposion wurde nach dem Mischen des ersten Kraters in der Tat gesungen, gesprochen und/oder Unterhaltung geboten.

Die Hypothese eines in Kap. $12+14$ gespiegelten christlichen Symposions läßt sich nicht schlagend beweisen, wohl aber mit einer auffällig langen Reihe von Indizien stützen. Zu Smith's Beobachtungen lassen sich weitere anfügen.

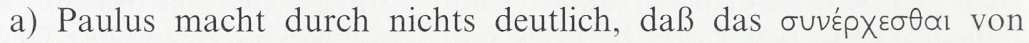
1Kor 14,23.26 zu einem anderen Zeitpunkt des Tages stattfindet als das

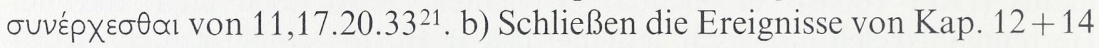
direkt an das Herrenmahl an, so entspricht Paulus dieser Ereignis-Abfolge in der Disposition seines Briefes! c) Paulus' Hymnus auf die Agape (1Kor

20 Smith, Obligation (s. Anm. 6) 181-184.216. Ähnlich und unabhängig von Smith Klauck, Herrenmahl (s. Anm. 2) 346-349. Seine Argumente gehen nicht über Smith hinaus. Zur Symposions-Analogie auch bereits H. Schürmann, Die Gestalt der urchristlichen Eucharistiefeier, in: ders., Ursprung und Gestalt. Erörterungen und Besinnungen zum Neuen Testament, KBANT, 1970, 87-90.

21 Die Praxis der von Plinius verhörten Christen darf nicht zu schnell in die Frühzeit hineinprojiziert werden: Plin., Ep 10,96,7 zufolge treffen sich die Christen an dem Tag, an dem sie sich versammeln, zweimal: Vor Sonnenaufgang (ante lucem) wird Christo im Wechsel gesungen und ethische Paränese zu Gehör gebracht. Später kommen die Christen noch einmal zusammen, um Speise zu sich zu nehmen (ad capiendum cibum). 
13) erinnert die antiken Leser an den Preis des Eros beim klassischen Symposion Platos (177 A-212 C, bes. $197 \mathrm{C}-\mathrm{E})$ : 1 Kor 13 kann als Anspielung auf den Symposionsrahmen der gottesdienstlichen Aktivitäten von 1 Kor $12+14$ interpretiert werden. d) Die korinthische Unordnung, die Paulus in 14,26ff. zu reglementieren versucht, paßt zu einem Symposionsrahmen. Auch bei paganen Symposia geht es nicht selten beim Weingenuß drunter und drüber: Mehrere sprechen auf einmal. Lukian (Symp 17) gibt davon einen Eindruck, wenn er ein philosophisches SymposionsGespräch parodiert. Daß diese Satire nicht am Leben vorbeigeht, zeigt z. B. das Reglement des religiösen Dionysos-Vereins der Jobacchen im Athen des 2. Jh.s n. Chr.: Der Verein hält es für nötig zu regeln, daß beim Mahl nur sprechen darf, wer an der Reihe ist ${ }^{22}$. Ähnlich versucht 1 Kor 14,27.30 f., das Durcheinanderreden zu unterbinden. - Das Drunter und Drüber ergibt sich vor allem dann, wenn kein Symposiarch leitet. Das Amt des Symposiarchen ist nicht mehr überall gebräuchlich ${ }^{23}$. Ähnlich leitet in Korinth niemand die christliche Zusammenkunft: Die pneumatokratische Gemeinde als ganze ist für das Geschehen verantwortlich $(14,26 \mathrm{ff}$.). Es gibt keinen einzelnen Vorsteher, sondern nur leitende Akte

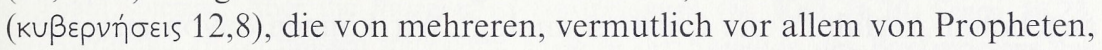
Lehrern und sozial höher Stehenden wie Stephanas (16,15f.) und dem Gastgeber Gaius (Röm 16,23) ausgeführt werden. e) 1Kor 14,26 läßt sich mit Aulus Gellius 7,13,12 vergleichen: Zum philosophischen Symposion bringt jeder Gast Diskussionsstoff mit. f) Der religiöse, gottesdienstliche Charakter des korinthisch-christlichen Symposions fände Parallelen in den liturgisch gestalteten Symposia paganer religiöser Vereine wie des der Jobacchen ${ }^{24}$.

Über Smith hinaus ließe sich auch fragen, g) warum Paulus das Singen in 14,26 an erster Stelle nennt. Der pagane Symposionsteil nach den secundae mensae beginnt in der Tat mit einem Gesang ( $\pi \propto \iota_{1} \mathbf{v}$ ), wie

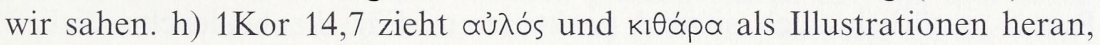
also die Instrumente, die geradezu klassisch zu einem Symposion gehören $^{25}$. Trompete und Schlacht fallen Paulus erst an zweiter Stelle $(14,8)$

\footnotetext{
$22 \mathrm{SIG}^{3} 1109$ Zeilen 108-110. Auch die Essener sprechen bei Tisch nur »der Ordnung nach« (Jos., Bell 2,133; 1QS 6,10 f.).

23 Plut., QuConv 1,4 (620 A); cf. Plato, Symp 176.

24 S. o. SIG 1109 und z. B. Smith, Obligation (s. Anm. 6) 155 f.

25 Siehe z. B. die Erörterung der beiden Instrumente bei Plut., QuConv 7,8 (712 F713 B). - Dem Text von 1 Kor 14 parallel argumentiert Plutarch in 713 B-D, daß Lyren- und Flötenmusiken beim Symposion möglichst nicht ohne gesungene, dem Verstand zugängliche Worte ( $\lambda$ ó $\gamma$ os) dargebracht werden sollten. Ähnlich argumentiert Paulus, daß Glossolalie ohne Übersetzung in verständliche Worte der GruppenGemeinschaft abträglich sei.
} 
ein. Wenn die in Kap. 14 geschilderten Aktivitäten in einem Symposionsrahmen stattfinden, erklärt sich gut, daß Paulus Flöte und Lyra zuerst assoziiert. i) Kaum besonders betont muß werden, daß bei einem Symposion nicht nur der Weingenuß (cf. 1Kor 11,21: angetrunkene Korinther), sondern auch der Flötenton ekstatische Phänomene stimuliert, wie sie von Paulus in 1 Kor $12+14$ ins Visier genommen werden. Plut., QuConv 7,8 (713 A) schildert schön, wie Wein und Flötenton zusammen sehr leicht den menschlichen Geist zur Ekstase emporheben. j) Zu einem Symposion hinter 1 Kor $12+14$ paßte schließlich, daß Nicht-Christen plötzlich in die Gesellschaft eintreten (1Kor 14,23f.). In der Umwelt stoßen häufiger neue Gäste zu bereits auf Touren gekommenen Symposions-Gesellschaften hinzu (s. u. Anm. 44).

Das einzige Problem für diese Hypothese besteht darin, daß 1 Kor 14,30 ein Sitzen der Teilnehmer voraussetzt, nicht ein Liegen, wie es bei einem Symposion der Fall wäre. Sind die Teilnehmer an der christlichen

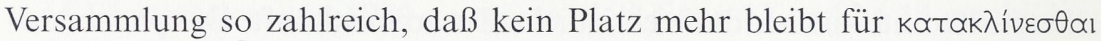

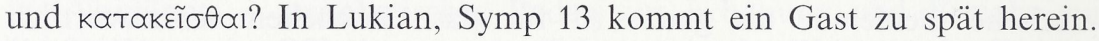
Weil für ihn kein Platz mehr zum Liegen ist, wird ihm ein Sitzplatz angeboten. Verfahren die Christen analog? Wir können davon ausgehen, daß die christliche Plenumsgemeinde Korinths (1Kor 14,23; Röm 16,23) nicht in einem normalen Speisezimmer, einem Triclinium, unterzubringen ist. Ein kaiserzeitliches Triclinium bietet höchstens 9-12 liegenden Personen Platz: Jedes der drei hufeisenförmig zusammengestellten Speisesofas wird von drei bis, wenn es hoch kommt, vier Personen belegt ${ }^{26}$. Setzen diese sich aufrecht, bieten sie einer noch einmal so großen Zahl Platz. Weitere Versammlungsteilnehmer müssen sich ins Atrium oder Peristyl setzen. Kann dann aber noch von einem Symposion gesprochen werden? Weingenuß (cf. 1Kor 11,21), Gesang (14,26), Flötenspiel (cf. 14,7) und ekstatische Glossolalie $(14,23)$ lassen sich nach dem Deipnon in geselliger Runde natürlich auch sitzend praktizieren. Für die heidenchristlichen Korinther besteht so zumindest die Möglichkeit, eine aufs Deipnon folgende gottesdienstliche Versammlung mit ekstatischen Elementen

26 Cf. z. B. W. H. Gross, Art. Triclinium, KP 5, 1975, 955. - Nach älterem griechischen Brauch lag oft sogar nur eine Person auf einer Kline. So z. B. Antiphanes (4. Jh. v. Chr.) bei Athenaios, Deipn 2,47 F. Archäologische Beispiele (5.-1.Jh. v. Chr.) für die griechische Ein-Personen-Couch bei Smith, Obligation (s. Anm. 6) 132.226.229.233.237; ferner bei S.G. Miller, The Prytaneion. Its Function and Architectural Form, Berkeley 1978, 219-224 (die griechische Durchschnittscouch maß ca. $1,8 \times 0,8 \mathrm{~m})$. Aber die griechische Sitte war nicht einheitlich: Auf griechischen Vasenbildern teilen sich auch mehrere Personen eine Couch. Cf. W. S. Ferguson, The Attic Orgeones, HThR 37, 1944, 80 Anm. 27 (bis zu fünf), sowie Plato,

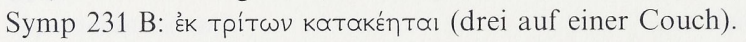


(14,26 ff.) als Symposionsersatz zu verstehen. Wie immer dem sei: Daß die in 1 Kor 14,26ff. genannten Aktivitäten am selben Abend nach dem Herrenmahlskelch folgen, bleibt eine begründete Möglichkeit ${ }^{27}$.

\section{Das korinthische Abendprogramm vor dem sakramentalen Herrenmahl - die Gründe des korinthischen Mißstands}

Wichtiger für das Verständnis von 1Kor 11,17-34 ist das Davor. Was fand in Korinth vor der Abfolge >Brotwort - Mahl - Kelchwort

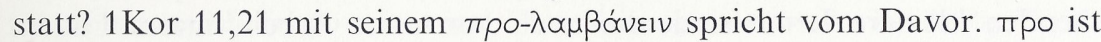
mit der überwältigenden Mehrzahl der $\pi \rho \circ \lambda \alpha \mu \beta \alpha \dot{v} v \omega$-Belege zeitlich zu deuten ${ }^{28}$. Einige Korinther essen ihre Abendspeise zwar in christlicher Versammlung - anders hätte die rhetorische Frage 11,22a keinen Sinn -, aber bereits vor dem beschriebenen Essenszeremoniell, das mit

${ }^{27}$ Für Stuhlmacher (Jesus [s. Anm. 4] 83) geht eine Ansprache dem Herrenmahl voraus - z. B. die Rezitation des 1 Kor, dessen Schluß den Übergang zum Herrenmahl spiegele. Aber die liturgischen Anspielungen (hl. Kuß 16,20, Segen 16,23, Anathema 16,22) müssen mitnichten auch in der Situation des Briefverlesens das Herrenmahl vorbereiten: Das Maranatha von 16,21 leitet auch Stuhlmacher zufolge (83) gerade nicht das Herrenmahl ein, sondern wird nach dem Herrenmahl gesprochen. Im übrigen muß Stuhlmacher bei seiner Rekonstruktion (83-85) annehmen, daß die später zum Herrenmahl eintreffenden ärmeren Gemeindeglieder das Verlesen von Briefen wie des 1 Kor nicht mitbekommen. Aber über dergleichen Mißstand entrüstet sich Paulus mitnichten, sondern nur, daß die später Eintreffenden beim Essen zu kurz kommen.

28 Bauer (Wörterbuch [s. Anm. 6] 1418) nennt unter der Sonderbedeutung »ergreifen« Gal 6,1; Weish 17,16; P.Oxy. 928; TestJud 2,5 als Belege für eine »mindestens stark

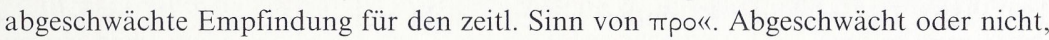
in allen Fällen ist der zeitliche Charakter gewahrt. TestJud 2,5: »Mit dem wilden Eber lief ich zusammen (um die Wette) und zerriß ihn, nachdem ich ihn vorher,

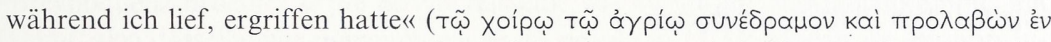

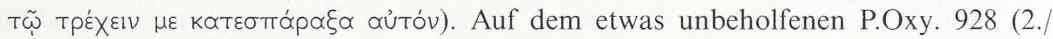
3. Jh. n. Chr.) ist der zeitliche Charakter besonders deutlich: Dem Mädchen Thais ist der Vormund gestorben, andere hegen bereits Pläne für sie; Apolinarius möge sich um das Mädchen kümmern, »bevor sie vorher weggeschnappt wird « von den Plänemachern ( $\pi \rho i v \pi \rho \circ \eta \eta \mu \varphi \theta \tilde{\eta} v \propto l)$. Das Halbsätzchen ist pleonastisch; das ist alles. In Weish 17,16 werden der ägyptische Bauer, Hirt und Arbeiter vorzeitig (d.h. in

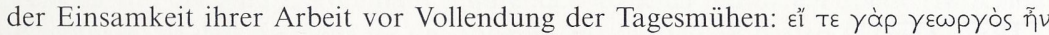

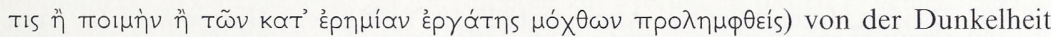
überrascht: Die Exodusplage der Finsternis ereilt sie. Auch in Gal 6,1 kann das Zeitliche nicht ausgeschlossen werden: vorzeitig (vor dem Gericht Gottes, auf das 5,$21 ; 6,9$ anspielen) bei einer Sünde ertappt werden. Bauers lexikalische Sonderkategorie ist angesichts dieser Texte kaum gerechtfertigt. Es bleibt so nur ein einziger Beleg für eine nicht-zeitliche Bedeutung $\left(\mathrm{SIG}^{3} 1170\right)$, der gleich - nach Anm. 32 zu besprechen sein wird. 
dem Brotwort beginnt. Sie sind dann bereits satt und zum Teil sogar angetrunken $(11,21)$, während andere beim aufs Brotwort folgenden Mahl hungern $(11,21)$ und nichts zu beißen haben $(11,22)$. Offensichtlich haben die ersteren bereits soviel vorher aufgegessen, daß beim Mahl zwischen Brot- und Kelchwort nicht mehr genügend Speise da ist, um wirklich jeden Teilnehmer zu sättigen. - Mit Theißen und Klauck ${ }^{29}$ sind die früh Kommenden als sozial Arriviertere zu identifizieren, die über genügend Zeit am Nachmittag verfügen, vermutlich eigene Häuser besitzen $(11,22 a)$

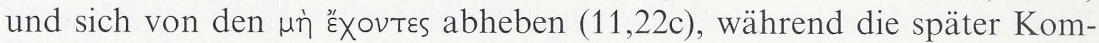
menden kleinere Leute sind, die noch von ihrer Arbeit, ihrem Laden, ihrem Sklavendienst aufgehalten werden.

Zwei Punkte müssen näher beleuchtet werden, um zu einer klareren

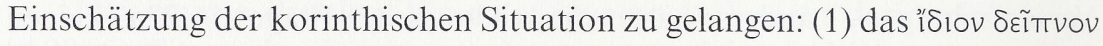

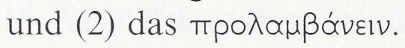

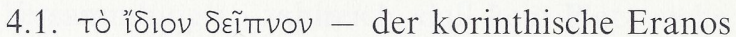

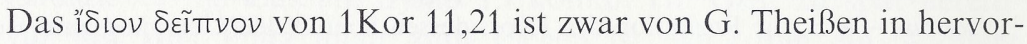
ragender Pionierleistung vor den Hintergrund graeco-römischer Mahlpraxis gestellt worden. Alle Möglichkeiten, die gegeneinander abzuwägen wären, sind dabei aber noch nicht ausgeschöpft worden ${ }^{30}$. Auch bleiben Zweifel an etlichen Punkten seiner Rekonstruktion.

Nach Theißen ${ }^{31}$ wurden die Speisen für das korinthische $\delta$ हाтाvov vom Gastgeber

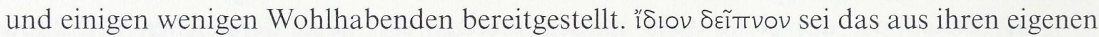

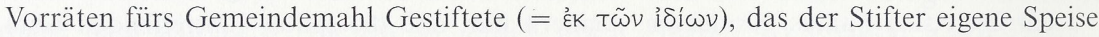
blieb, solange es nicht durch die eucharistische Liturgie eine Speise des Herrn und damit die gemeinschaftliche Speise aller Eucharistieteilnehmer wurde.

Doch geselle sich für ı́øıov noch eine zweite Bedeutungsnuance hinzu (Theißen 184-186). Die reicheren Korinther stifteten nicht nur die Speisen, sie behielten sich auch Teile von diesen Speisen auf eigenen Gedecken (an möglicherweise getrennten

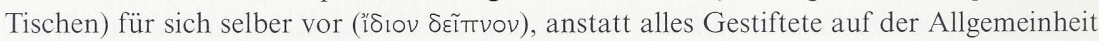
zugänglichen Platten anzubieten.

Für diese Sitte verweist Theißen auf Eratosthenes (FGH 241 Frgm. 16) und Plut., QuConv 2,10 (642 F-644 D). Plutarch erörtert ausführlich die Alternative, ob ein Gastgeber jedem Gast eine Portion zuteilen solle oder ob die Gäste selber von gemeinsamen Platten zulangen sollten. Tò ísıov bezeichnet in $644 \mathrm{C}$ in der Tat die jedem Gast vom Gastgeber zugeteilte Portion. Hagias vertritt die These, daß dieses Aufteilen des

29 Cf. Theißen, Integration (s. Anm. 4) 182 f.185 f.; Klauck, Herrenmahl (s. Anm. 2) 293.

30 Auch trotz glänzender Beobachtungen von Klauck, Herrenmahl, 293 f.296f., nicht. Er ist v. a. an den religionsgeschichtlichen Hintergründen des massiven Sakramentalismus der Korinther interessiert (331.370 f.).

31 Integration, 183 f.; gefolgt von z. B. J. Murphy-O'Connor, St. Paul's Corinth, Wilmington, Delaware 1983, 161. 
Fleisches und Brotes in Portionen die Gemeinschaft störe (643 A - E). In der Fortsetzung des Textes kontert Plutarch's Großvater Lamprias dem Hagias (643 E-644 D), ohne Zweifel Plutarch's eigene Meinung wiedergebend (cf. 642 F): das Essen von gemeinsamen Platten führe zu Futter neidenden Rangeleien und gefährde so gerade die Gemeinschaft. Das Aufteilen durch den Gastgeber sei gerechter und der Gemeinschaft in keiner Weise abträglich, vorausgesetzt, die Portionen seien gleich groß bemessen (644 D).

Nach Theißen (190f.) war letztere Bedingung in Korinth nicht erfüllt: Die Reicheren hätten über größere Portionen verfügt (190: Umweltparallelen). Auch hätten sie sich gemäß der Sitte, daß Gäste unterschiedlichen Kalibers zuweilen Speisen unterschiedlicher Qualität zu essen bekamen ${ }^{32}$, die besseren Stücke des Mahls für sich selber reserviert: nämlich das über Brot und Wein hinausgehende ő $\psi$ ov, also Fisch, Fleisch und ähnliches. Für die anderen Christen hätten nur Brot und Wein bereitgestanden, die mit den Einsetzungsworten an alle Teilnehmer verteilt worden seien (Theißen 191 f.).

Drittens hätten die reicheren Korinther diese ihnen reservierten Portionen nicht nur vor dem Herrenmahl vorweggegessen; sie hätten sich auch noch während des Herrenmahls weiter an ihnen gütlich getan; nur Brot und Wein seien durch die Einsetzungsworte der Gemeinschaft zur Verfügung gestellt worden. Theißen (189) beruft sich

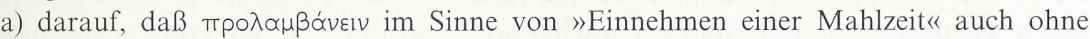

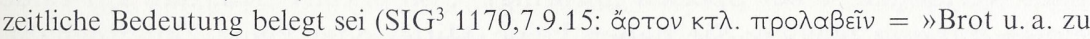
sich nehmen «). Doch ist mit dieser Inschrift des epidaurischen Asklepieions lediglich ein Beleg geliefert, der zudem unsicher bleibt. Bereits die SIG ${ }^{3}$-Fußnote bemerkt, daß es sich um eine Verwechslung des Steinmetzen handeln mag: Nicht $\pi$ po-, sondern

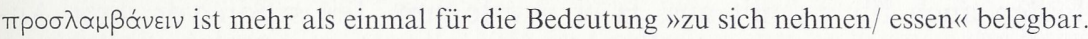

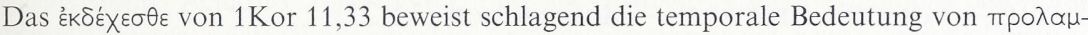
ßóvelv in 11,21. Für Theißens sowohl zeitliches als auch nicht-zeitliches Verständnis von

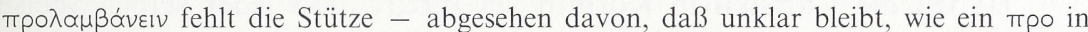
ein und demselben Wort im selben Satz gleichzeitig zeitlich und nicht-zeitlich fungieren

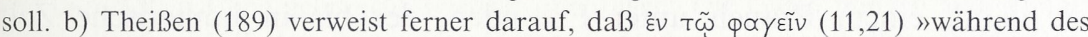

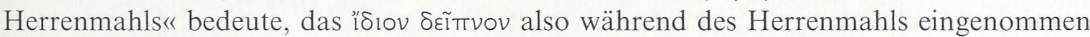
wurde. Doch läßt sich der Argumentations-Spieß auch umdrehen. Ist einmal zugestan-

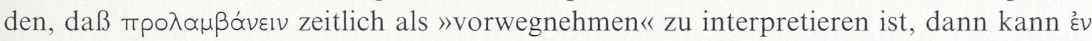

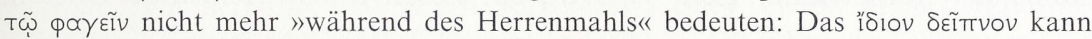
nicht dem Herrenmahl vorweggenommen werden, während das Herrenmahl stattfindet.

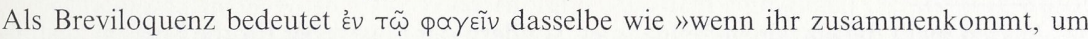

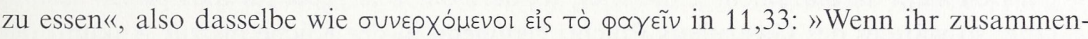
kommt, um zu essen«, nehmt ihr vorweg, anstatt zu warten. 11,21a (Vorwegnehmen) und 11,33 (Warten) korrespondieren deutlich miteinander; es liegt deshalb nahe, 11,21a im Lichte von 11,33 zu interpretieren.

Nach allem überzeugt kaum, daß die Reicheren auch während des dem Brotwort folgenden Herrenmahles einerseits ihre für sich reservierten Portionen weiteraßen und andererseits von der zum Herrenmahl gehörenden gemeinschaftlichen Speise (Brot und Wein) nahmen, so daß sie mehr als die anderen zur Verfügung hatten (Theißen 189f.), ja etliche der anderen hungrig blieben (191). Fällt diese Erklärung des Hungers der $\mu \grave{\eta}$

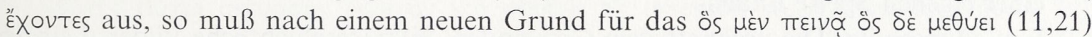
gesucht werden.

32 Plin., Ep 2,6; Juv., Sat. 5, bes. 5,162; Martial 3,60; 1,20; 4,85; 6,11; 10,49. Weitere Belege zur unterschiedlichen Behandlung beim Mahl bei Klauck, Herrenmahl, 293 f. 
Hier soll als Alternative ein modifizierter Umwelt-Hintergrund für

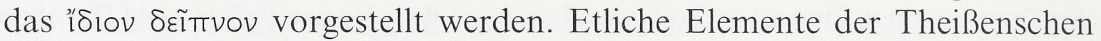
Rekonstruktion der korinthischen Situation werden wiederkehren, andere werden ersetzt werden. Wie Rekonstruktionen in der Archäologie bleiben beide Entwürfe hypothetisch: Mithilfe von Umweltanalogien rekonstruieren sie ein antikes Situations->Bauwerk , das im Quellenmaterial für die spezielle Situation (1Kor 11) nur in Teilen sichtbar wird. Wichtig wird sein, die rekonstruierten Teile möglichst glatt den vorhandenen Bauteilen einzupassen.

Rekonstruktion. Die Reicheren verzehren vor dem mit dem Brotwort beginnenden Gemeindemahl Speisen, die sie offensichtlich selber mitgebracht haben. Die wahrscheinlichste Rekonstruktion der korinthischen Abendversammlung muß lauten, daß nicht der Gastgeber, der die Räum-

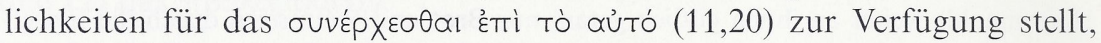
auch die Speisen für das $\delta \varepsilon \tilde{T} \pi v o v$ liefert, sondern daß jeder Teilnehmer nach Vermögen selber Speisen mitbringt ${ }^{33}$. So erklärt sich, daß am Ende einige hungrig bleiben: Sie haben keine Mittel oder keine Zeit ${ }^{34}$ gehabt, sich vorher selber eine Speise zur Mitnahme vorzubereiten. Deshalb bleiben sie hungrig. Denn das Mitgebrachte der anderen reicht nicht in allen Fällen auch für sie mit aus; ja es wurde zum Teil schon vor ihrer Ankunft - vor dem Brotwort - aufgegessen $(11,21)$.

Haben die Christen in Korinth vereinbart, daß jeder selber Speise

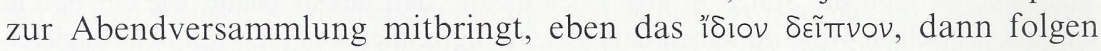
sie damit einem Brauch unter Freunden, der bis in homerische Zeit zurückzuverfolgen ist, aber auch noch für das 2. Jh. n. Chr. (Athenaios, Aelius Aristides, Lukian) belegt ist ${ }^{35}$. Dieser Typ gemeinsamer Mahlzeit heißt seit homerischer Zeit ${ }^{36}$ हैpavos, ein Essen auf gemeinsame Kosten,

33 Wären nicht die einzelnen Teilnehmer, sondern der Gastgeber für die Speisen zuständig, so wäre es des Gastgebers Pflicht, genügend in der Küche bis zur Ankunft der geladenen, aber später eintreffenden Christen zurückzuhalten, so daß diese nicht hungrig bleiben. Aber Paulus läßt nichts von der Vernachlässigung solcher Pflicht erkennen.

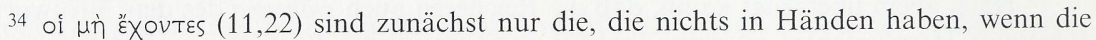
Christen zusammenkommen. Mindestens zwei Gründe sind denkbar. Entweder handelt es sich um Arme, die nicht für sich selber sorgen können, oder um solche, die aufgrund ihrer Arbeit vor der Gemeindeversammlung keine Zeit zur Zubereitung einer eigenen Speise finden.

35 E. v. Dobschütz (Die urchristlichen Gemeinden. Sittengeschichtliche Bilder, Leipzig 1902, 50) erkannte richtig, daß jeder korinthische Christ seinen Speiseanteil mitzubringen hatte. Unrichtig identifizierte Dobschütz jedoch diese Praxis als von griechischer Sitte abweichend.

36 Homer, Od 1,226f. mit (Schol.) 11,414f.; Hesiod, Op et Dies $722 \mathrm{f}$. 
zu dem jeder Teilnehmer etwas mitbringt ${ }^{37}$. Die Gäste bringen ihren

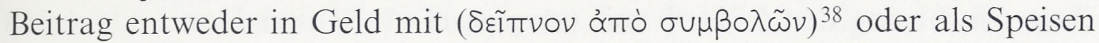
in Körben ( $\delta \varepsilon \tilde{i} \pi v o v$ åmò $\sigma \pi v p i ́ \delta o s)^{39}$. Anschaulich beschreibt Aristophanes,

37 Cf. F. Orth, Art. Kochkunst, PRE 11/1, 1921, 948.957; E. Ziebarth, Art. हैpavos, PRE 6/1, 1907, 328; ders., Das Griechische Vereinswesen, Leipzig 1896, 15; A. Mau, Art. Convivium (s. Anm. 8) 1201 f.; A. Hug, Art. omupis, PRE II 3/2, 1929, 1891 f.;

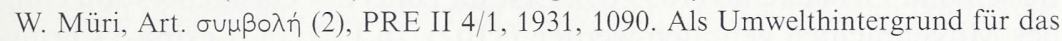

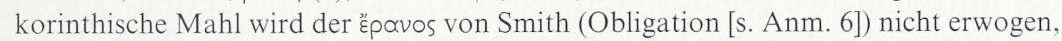
obwohl er die Sitte des हैpavos in anderem Zusammenhang beiläufig erwähnt (103.142). Nichts vom हैpavos bei Murphy-O'Connor, Corinth (s. Anm. 31) $153 \mathrm{ff}$. Klauck (Herrenmahl, 293) verwendet vier Zeilen auf die mögliche Beziehung des Eranos zu 1 Kor 11 und ist zu sehr auf den Eranos als feste Vereinsform (cf. u. Anm. 38) fixiert.

38 Athen., Deipn 8,365 DE. Athenaios interpretiert hier Menander-, Alexis- und Hegesanderstellen (Hegesander, FHG IV, 419), d. h. Texte aus dem 3./4. Jh. v. Chr. Er

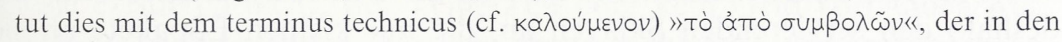
drei Texten gerade nicht vorkommt. Athenaios reflektiert so seine eigene Gegenwart

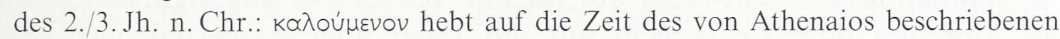
Dialogs ab, an dem fiktiv z. B. der Arzt Galen (gestorben 199 n. Chr.) und der Jurist Ulpian teilnehmen. Zum Geldbeitrag s. weiter Eust., Iliad 16,764; 17,578; Schol. Aristoph., Acharn 1210 f.; in SIG $^{3} 1045$ der Geldbeitrag zum Festmahl an den Itonia in Arkesine. Auch als Lehnwort im Lateinischen bezeichnet symbola den Geldbeitrag jedes Teilnehmers zu einem gemeinsamen Mahl: Terenz, Andr 88 und Eunuch $540-$ 544; Plautus, Curculio 474, Stichus 438 und Epidicus 125. - Gellius (7,13,12; ca. $130-180$ n. Chr.) gebraucht symbola übertragen: Die Gäste bringen zum Dinner Diskussionsstoff statt Essen oder Geld mit. Ähnlich verwendet Plutarch (QuConv 6,8 [694 B]) "̌́pavos kolvós übertragen: Bei der Tischdiskussion »haben wir diese Argumente als gemeinsamen Eranos zusammengetragen«. - Einer der Teilnehmer wurde mit der organisatorischen Vorbereitung eines solchen Mahles beauftragt (Terenz, Eunuch 540-544; cf. Terenz, Andr 88). - Oft führte die Schmauserei auf gemeinschaftliche Kosten zur Wiederholung: Aus dem einmaligen Geldbeitrag wurde ein regelmäßiger, ein geschlossener Verein entstand: Cf. z. B. Arist., EthNic 1160a,20 (Eranos als Speiseverein) und Ziebarth, Art. हैpavos (s. Anm. 37) 330; ders., Vereinswesen, 15 f.135.193 (kultische Eranoi ab 3. Jh. v. Chr.). Einige Vereine forderten von ihren Mitgliedern Beiträge nicht nur in Geld, sondern auch in Naturalien. Das Collegium von Diana und Antinous, ein Begräbnisverein im italischen Lanuvium des Jahres 136 n. Chr. (ILS 7212), forderte von jedem Mitglied neben Geld eine vini boni amphora (Zeilen $1 / 21+2 / 7-8$ ), die offensichtlich bei den gemeinsamen Mahlzeiten (cf. 2/14-16) aufgetrunken wurde.

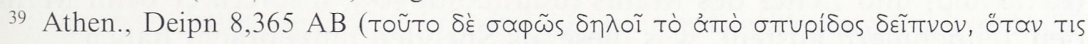

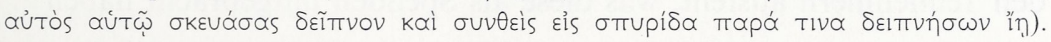
Athenaios reflektiert hier wieder die Gegenwart seines Dialogs, also das 2. Jh. n. Chr.:

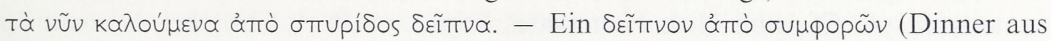
Beiträgen) bei Lukian, Lexiph 6; undeutlich bleibt aber, ob es sich um Geld- oder

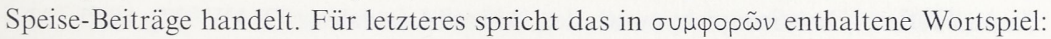
Die Vokabel bedeutet zugleich »Katastrophen«, womit Lukian auf die Speisen selber

14 Zeitschr. f. d. neutest. Wiss., 82. Band 1991 
Acharn 1085-1149 die Sitte. »Komm schnell zum Deipnon«, lädt ein

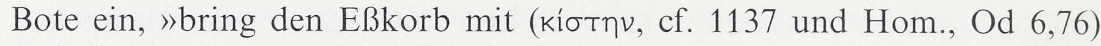
und die Kanne« (1085f.). Der Scholiast merkt an, daß die Einladenden Kränze, Parfums und Süßigkeiten bereitstellen (cf. 1090 - 1093), während

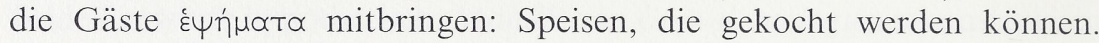
»Schließ das Haus und pack ein Deipnon ein« (1096). »Sklave, hol mir den Eßkorb her« (1098). Eingepackt werden Fischfilet, Tauben-, Hasenfleisch und Gebackenes (1099 ff.). Erst im Haus des Gastgebers soll einiges des Mitgebrachten gebraten werden (1102). In Lukian, Lexiph 13 bringen neu zu einem Symposion hinzugekommene Gäste (9) selber Wein, Trinkgerät und Desserts mit.

Auch Xenophon, Mem 3,14,1 beschreibt, wie die Deipnon-Teilnehmer ihr öyov von zu Hause mitbringen, also alles, was zum Brot gegessen wird, insbesondere Fleisch, Fisch, doch auch Gemüse. Die einen bringen

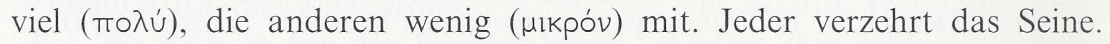
Sokrates empfindet letzteres als Mangel an Gemeinschaftssinn. Er weist deshalb den servierenden Sklaven an, die nur kleinen Eßpakete an sich zu nehmen und sie entweder auf für alle Teilnehmer zugänglichen Platten auszubreiten oder sie gerecht auf die Teller aller zu verteilen (

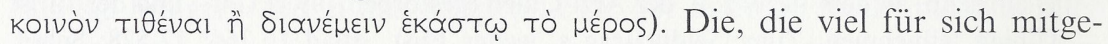
bracht haben, werden dadurch blamiert (ñoxúvovTo) und gezwungen, auch ihre Portionen der Allgemeinheit zur Verfügung zu stellen ( $\varepsilon \dot{r} \dot{i} \theta \varepsilon \sigma \propto v \nu$ oũv

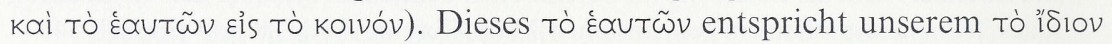

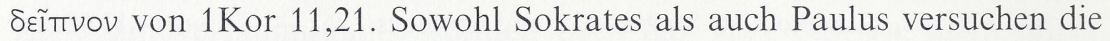
Eranos-Sitte des Verzehrens von Mitgebrachtem in gemeinsamer Tischrunde vor Mißbrauch zu schützen: Sie soll nicht dazu führen, daß einige schlemmen, während andere zu kurz kommen. Das Resultat der sokratischen Maßnahme lautet: Die viel mitbrachten, »verfügten nicht über

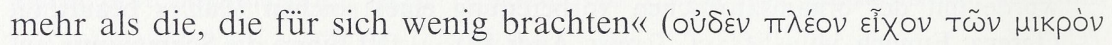
фвроне́v

Auch kultische Mahlzeiten konnten als Eranos organisiert sein. Im 2. Jh. n. Chr. bezeichnet Aelius Aristides, Sarap 54,20 ff. (Dindorf) die Sarapis-Kultmahlzeit als Épavos, bei dem der Gott - als દ́pávwv $\pi \lambda \eta \rho \omega \tau \eta \dot{s}$ - wirklich gegenwärtig sei inmitten derer, die sich in seinem Namen ( $к \propto T^{\prime}$ aủTóv) versammeln und Speisen-Spenden mitbringen. Sarapis

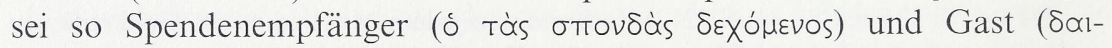

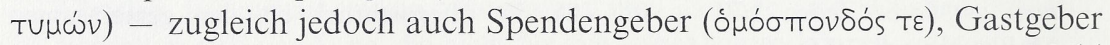

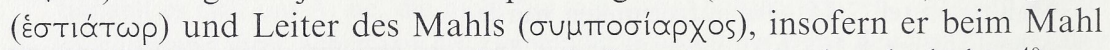
den Teilnehmern austeilt, was diese als Spenden mitgebracht haben ${ }^{40}$.

anspielt. - Cf. schließlich Pherecrates Frgmt. (5. Jh. v. Chr.) bei Athenaios ebd. sowie Xen., Symp 1,11.

40 A. Höfler (Der Sarapishymnus des Ailios Aristeides, TBAW 27, 1935, 93-98) versäumt in seinem Kommentar, den हैpavos-Begriff zu erklären. Er vermutet deshalb 
Kulturgeschichtlich erhält sich die Mahlform des Eranos über Jahrtausende. Ein gemeinsames Essen, zu dem jeder eine Speise beisteuert, heißt auf Amerikanisch »Potluck meal «, auf Neudeutsch zuweilen »BottleParty«, unter freiem Himmel »Picknick«. Solange Menschen im Freundeskreis gemeinsam essen, aber nicht einer Person allein die Gastgeberpflichten aufbürden wollen, wird es diesen homerischen हैpavos geben.

Interpretieren wir 1 Kor 11 in diesem Licht, so treffen im Haus des christlichen Gastgebers die reicheren Korinther am Nachmittag früher als die sozial Niedrigeren ein. Da bei einem Mahl unter Freunden in der Regel die Teilnehmer Platz nehmen, wo sie wollen, und das sonst übliche Platzanweisen durch den Gastgeber oder dessen Nomenclator entfällt ${ }^{41}$, lagern sie sich ungezwungen im Triclinium des Gastgebers und packen ihr

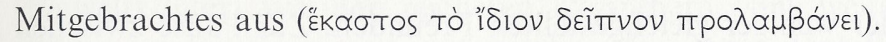

Die anderen Christen aus niedrigeren sozialen Schichten treffen erst später ein. Ihre mitgebrachten Portionen fallen entweder bescheiden aus oder sie existieren nicht, weil keine Zeit oder kein Geld vorhanden war, sie zu Hause vorzubereiten. Von dem bereits mehr oder weniger verzehrten Mitgebrachten der Reicheren ist darüber hinaus nicht mehr genügend übrig, um alle später Gekommenen zu sättigen ${ }^{42}$. Etliche von diesen bleiben deshalb hungrig ( $\pi \varepsilon ı v \tilde{\alpha})$.

Obendrein werden die später Kommenden kaum mehr im Triclinium Platz finden ${ }^{43}$. Sie müssen auf Atrium oder Peristyl ausweichen, was eine weitere Benachteiligung bedeutet. Der christliche Eranos in Korinth wird so nicht nur wie bei Xenophon durch unterschiedlich große Eßpakete zum sozialen Problem, sondern auch durch das Fehlen des gemeinsamen

irrig, derjenige, der seine Freunde zum Sarapismahl einlade, stifte die Speisen

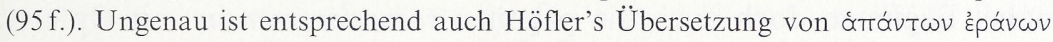
$\pi \lambda \eta \rho \omega \tau \eta \dot{s}$ als $>$ die ehrende Krone bei allen Festmahlen<. $\pi \lambda \eta p \omega \tau \eta \dot{s}$ ist vielmehr der Einsammelnde, der die Zahl der zu einem Eranos Beitragenden voll macht (Belege z. B. H. G. Liddell - R. Scott, A Greek-English Lexicon II, Oxford 1940, 1420). Auf Sarapis übertragen: Er sammelt die von den Eranosteilnehmern mitgebrachten Speisen ein (= Spendenempfänger), um sie als Symposiarch an die Mahlrunde

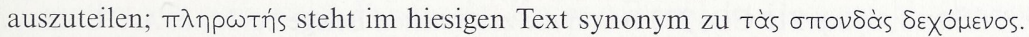

41 Athen., Deipn 2,47 E; Plut., QuConv 1,2.

$42 \mathrm{Daß}$ die Reichen ihr Mitgebrachtes beim Eintreffen der später Kommenden nicht der Allgemeinheit zur Verfügung stellen wollen, wird von Paulus nirgends angedeutet. Das Problem ist vielmehr, daß die Reichen ihr Mitgebrachtes schon weitgehend aufgegessen haben, so daß sie es später gar nicht mehr wirkungsvoll mit anderen teilen können.

${ }^{43}$ Hierauf weist mit Recht Murphy-O'Connor hin (Corinth [s. Anm. 31] 158f.). Er nennt nur das Atrium als Reserve-Räumlichkeit. Doch bot sich zu diesem Zweck ebenso das Peristyl an oder weitere ans Peristyl angrenzende Räume, in die für die Dauer einer größeren Gesellschaft Eßmöbel gestellt werden konnten. Cf. z. B. Gross, Art. Triclinium (s. Anm. 26). 


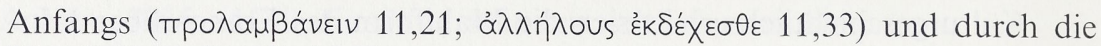
Unmöglichkeit, alle in einem normal großen Triclinium unterzubringen.

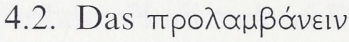

Im Fragebrief der Korinther (cf. 1 Kor 7; 8-10; $12-14 ; 16,1-4$ ) spielt das Problem von 1 Kor 11,17-34 keine Rolle. Wir können davon ausgehen, daß die reicheren »Voresser« in Korinth ihr Verhalten als unanstößig empfinden. Wie ist das möglich? Es ist dann möglich, wenn sie ihr Verhalten im Rahmen der hellenistisch-römischen Mahlpraxeis deuten. Vermutlich so - jedenfalls hätten sie folgendes zu ihrer Entlastung vorbringen können: Die Reicheren interpretieren ihr »Voressen« auf EranosBasis als regelrechtes $\delta \varepsilon \tilde{T} \pi v o v$ (cena/primae mensae; cf. 1Kor 11,21a) unter sozial mehr oder weniger gleichgestellten Freunden. Zur Pause zwischen

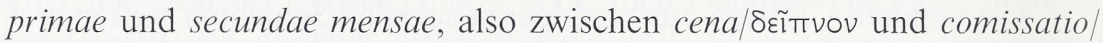

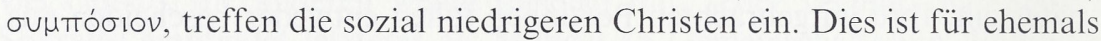
pagane Korinther nichts Außergewöhnliches: Nach dem Deipnon können sich irgendwann neue Gäste mit oder ohne Mitgebrachtem zum Symposion hinzugesellen ${ }^{44}$. Die Sitte, bei Freunden nach dem Mahl zum Gelage - auch uneingeladen - zu erscheinen, ist sogar sprichwörtlich, wie im 2. Jh. n. Chr. der Paroemiograph Zenobius notiert ${ }^{45}$. In diesem Licht machen sich die Reichen kein schlechtes Gewissen wegen ihres »Voressens « an den primae mensae. Im paganen Bereich fragt niemand die neu $\mathrm{zu}$

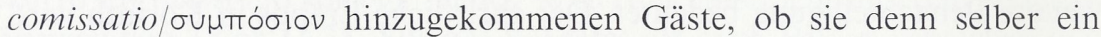
ausreichendes $\delta \varepsilon \tilde{i} \pi v$ ov genossen oder ob und wieviel sie sich zu den secundae mensae mitgebracht haben ${ }^{46}$.

Das Brotwort kann von den reichen »Voressern« entsprechend als Beginn der secundae mensae gedeutet werden. Diese Assoziation liegt nahe: Beginnen doch auch die paganen secundae mensae mit Opferritus und religiösen Akklamationen (s. o.). Als beziehungsreich muß sich für ehemalige Heiden zudem ausnehmen, daß vor den paganen secundae mensae der Genius des Kaisers angerufen wird. Nach Horaz, Od 4,5,31 f.

44 Cf. Plato, Symp 212 CD; 223 B und die zahlreichen Belege bei Mau, Art. Comissatio (s. Anm. 8) 618 u. -619 o.: Neue Gäste stoßen zu bereits auf Touren gekommenen

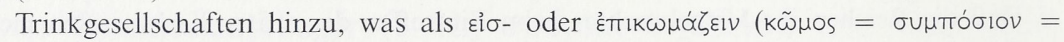
comissatio) bezeichnet wird (Lukian, Lexiph 9; Athen., Deipn 5,180 A). In Lukian, Lexiph 13 erscheinen die Neuankömmlinge mit selber Mitgebrachtem.

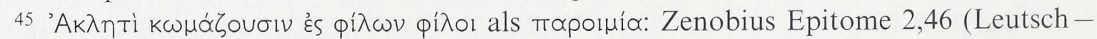
Schneidewin).

46 Hier bekommen diejenigen der von Theißen (Integration [s. Anm. 4] $190 \mathrm{ff}$.) und Klauck (Herrenmahl [s. Anm. 2] 293 f.) zitierten Umweltstimmen ihren Platz, die unterschiedliche Qualität und Quantität der Eßportionen beim Mahl billigten (cf. o. bei Anm. 32) und so dazu angetan waren, den Korinthern ein gutes Gewissen zu bereiten. 
wird der Kaiser »als Gott zu den alteris mensis hinzugezogen « (alteris te mensis adhibet deum); ihm wird ein Trankopfer gespendet ${ }^{47}$. Der christliche Brotsegen ersetzt dieses Element des Herrscherkults; der Kyrios Jesus Christus wird sakramental präsent.

Wenn die voressenden Korinther den sakramentalen Akt des Herrenmahls als dem Tafeln an den secundae mensae entsprechend verstehen, so tun sie etwas, was gang und gäbe in der Umwelt ist: Religiöse Essen, kultische Opfermahlzeiten, weichen in der Umwelt gerade nicht vom Muster normaler Mahlzeiten ab. Sie beziehen ihren kultischen Charakter nicht aus einer anderen Mahlform, sondern aus der speziell kultischreligiösen Interpretation dessen, was auch sonst bei einem normalen Bankett stattfindet ${ }^{48}$. Das Essen an den secundae mensae kann in diesem Umweltkontext von den reicheren Korinthern ohne weiteres als massiv sakramentales Essen gedeutet werden, das gegen Unbill feit ${ }^{49}$. Unsere Gegenüberstellung von paganem Mahlablauf und christlichem Tafeln in Korinth lenkt so mitnichten zu der alten These zurück, daß die Korinther das Herrenmahl zu einer gewöhnlichen Mahlzeit profaniert hätten ${ }^{50}$. Die Umwelt lehrt, daß gerade die gewöhnliche Mahlzeit durch entsprechende

47 Cass. Dio 51,19,7 bereits fürs Jahr 30 v. Chr. Die weiteren Belege s. o. Anm. 15.

48 S. o. Anm. 7.

49 »Sakramental« hier = durch eine rituelle Handlung wird die Gottheit mit ihrer für den Menschen sich positiv auswirkenden Kraft unmittelbar präsent. Diese Gleichung vermag eine magische Handlung aus dem Definitionsbereich nicht auszuschließen mit Absicht, denn wir haben keine Anhaltspunkte, daß den Korinthern eine klare Grenze zwischen »magisch« und »sakramental« bewußt gewesen wäre. Zu den Definitionsschwierigkeiten Klauck, Herrenmahl, 37 f. Zum korinthischen Sakramentalismus cf. die korinthische Vikariatstaufe (1Kor 15,29) und v.a. 10,1 ff.: Paulus muß klarstellen, daß die Sakramente, Taufe und Herrenmahl (10,2-4), nicht in einem Heilsautomatismus vor jeglichem Straucheln schützen (10,5 ff.). Paulus selber formuliert sakramentalistisch, daß in der Taufe der Geist »getrunken « $(12,13)$ und

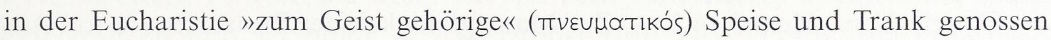
werden (10,3-4). Kein Zweifel kann bestehen, daß sowohl Paulus als auch die Korinther von einer realen Präsenz des Kyrios während des Herrenmahls überzeugt sind. Hilfreich sind die von Klauck (Herrenmahl, 373f.) im Anschluß an J. Betz entwickelten Kategorien der Realpräsenz: Paulus und die Korinther hegen zumindest die Vorstellung einer »prinzipalen Realpräsenz«: »Der erhöhte Kyrios ist personal zugegen ... als Princeps, das heißt als Tischherr und Gastgeber«. Als Parallele sahen wir bereits Aelius Aristides, Sarap 54,21 ff. (Dindorf): Sarapis ist »Tischgenosse, Gastgeber« und »Leiter« des Opfermahls zugleich. Paulus selber rückt in 1 Kor 10,18 - 22 das Herrenmahl an die Parallele zu pagan-kultischen Opfermahlzeiten heran. - Ob darüber hinaus von Paulus oder den Korinthern eine Realpräsenz in den Mahlelementen vorgestellt wird, ist eine andere Frage (s. u.).

50 So z. B. v. Dobschütz, Gemeinden (s. Anm. 35) 24; J. Weiss, Der erste Korintherbrief, Göttingen 1910, 283. 
Interpretation - und durch einige diese Interpretation ausdrückende Worte und Akte - zum massiv kultisch-sakramentalen Essen wird.

Die secundae mensae als sakramentales Mahl zu verstehen, ist den Korinthern schließlich auch deshalb möglich, weil dort in der Regel mehr serviert wird, als was uns als »Nachspeise « vertraut ist. Die Gerichte an den »Zweittischen « müssen nicht immer süß sein; Varro empfiehlt würzige

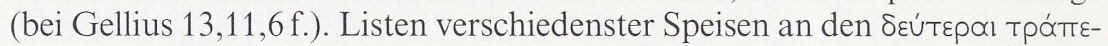
$\zeta \propto$ l bietet Athenaios ${ }^{51}$. Eine ${ }^{52}$ nennt zum Beispiel Gebäck, Obst, Gemüse,

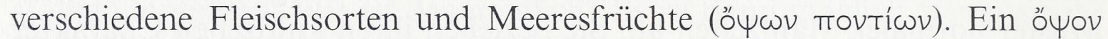
ist aber dadurch definiert, daß es $z u$ Brot gegessen wird ${ }^{53}$. Zum Nachtisch gereichtes Brot findet sich auch bei Athenaios, Deipn 3,109 DE ${ }^{54}$.

Die Analogien zwischen paganem Deipnon-Symposion-Programm und christlicher Zusammenkunft mit Sättigungsmahl und eucharistischem Sakrament seien in einer Tabelle zusammengefaßt - Analogien, wie sie von einem ehemaligen Heiden, der sich ohne Gewissensbisse die Freiheit zum »Voressen « herausnahm, empfunden werden mußten:

- Götterakklamation

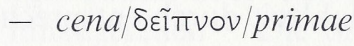
mensae

Beginn der secundae mensae:

- mit Opfer verbundenes

Anrufen der Laren und

- das »Voressen« der reicheren Korinther

Genien des Hausherrn und

des Kaisers

51 Deipn 14,639 Bff., bes. 640 B-F; 641 BCF; 642 ADEF; 643 A-D. In $641 \mathrm{~F}$ (= Antiphanes 4.Jh. v. Chr.) Ei, Hasenfleisch, Krammetsvögel, Honigkuchen. Daß auch noch im 2. Jh. n. Chr. die »Zweittische« so üppig gedeckt sind, attestiert Athen., Deipn 14,641 C.643 A, wo in die Situation des Dialogs (2. Jh. n. Chr.) gesprungen wird.

52 Deipn $640 \mathrm{BC}$ (= Euripides und Eubulus).

53 Cf. z. B. Xen., Mem 3,14,2. - Zur Mannigfaltigkeit der Brotsorten (åpтoı) Athen., Deipn 3,109 B-116 A. Auch eine ephesische Inschrift nennt vier verschiedene Brotsorten von grobem bis zu feinstem Weizenbrot (Die Inschriften von Ephesos III, ed. H. Engelmann u. a., Bonn 1980, Nr. 938).

54 Athenaios zitiert hier Lynceus von Samos (4./3.Jh. v. Chr.). Auch das Feingemahlene zum Nachtisch bei Athen., Deipn 14,642 A wird Brot gewesen sein (s. C. B. Gulick [ed.], Athenaeus, The Deipnosophists VI, LCL, 1937, 465 Anm. e). - Brot in paganen OpferKontexten: Athen., Deipn 3,109 EF Opferbrot für die trauernde attische Demeter; 110 B für Kronos, es kann von jedermann/frau im Kronostempel verzehrt werden; $110 \mathrm{C}$ für Hekate; 114 BC für aetolische Götter; 111 E ein mit einem bacchischen Ritus verbundenes Brot; 115 A bei Opferfesten an das Volk verteiltes Gerstenbrot; 111 B in Prozessionen getragenes Brot; SIG 438 ungesäuertes Opferbrot in Delphi; cf. auch Opferkuchen bei z. B. Aristoph., Thesm 285; Athen., Deipn 14,645 A. Kultischer Gebrauch von Brot war den Heidenchristen Korinths nichts Neues. 
- secundae mensae

(oft mit Gästen, die neu

hinzugekommen waren)

- ein Schluck ungemischten

Weines für den ớratòs

$\delta a i ́ \omega \omega v$

- Mischen des ersten Kraters, Trankopfer, Gesang

- Trinken, Konversation, Musik, Gesang, Unterhaltung in lockerer Folge
- das sakramentale Essen des Herrenmahls

- Kelchwort

- Trinken

- die gottesdienstlichen Aktivitäten von Kap. $12+14$ (bes. 14,26 ff.):

Gesang, Lehren, Prophetien, Glossolalien (mit Übersetzungen); keine geregelte Abfolge.

Die Lieb- und Achtlosigkeit der korinthischen Reichen gegenüber den Hungrigen resultierte nach allem wahrscheinlich daraus, daß jene ohne viel Nachdenkens Speise-Sitten ihrer paganen Vergangenheit im christlichen Kontext weiterpraktizierten. Das Verhalten der korinthischen Reichen wird so am besten verständlich ${ }^{55}$.

Diese unreflektierte Prolongation vorbaptismalen Verhaltens läßt sich auch an einem weiteren Punkt demonstrieren. Wenn die sozial niedriger Stehenden erst später zur korinthischen Versammlung eintrafen und dann nicht mehr im Triclinium, sondern nur noch in Atrium und Peristyl Platz fanden (s. bei Anm. 43), so spiegelt sich auch in diesem Zug ein vorbaptismaler Habitus: Sozial niedriger stehende Klienten wurden vom Patron im Atrium empfangen und abgefertigt (z. B. Martial 12,68,1 f.; $9,100,2 ; 4,40,1 ; 3,38,11)$. Auch dieser Umwelthintergrund war dazu angetan, den reicheren Korinthern ein gutes Gewissen in ihrer Abendmahlspraxis zu bereiten. Hatten sie doch bereits sehr >christlich konzediert, sozial Niedrigere zu den secundae mensae überhaupt zuzulassen: Bei Gastmahl und Symposion der Umwelt tafelten in aller Regel sozial gleichgestellte qí̉oı (cf. z. B. Anm. 45) miteinander und nicht auch sozial niedrigere Sklaven und Arme. In dieser Beziehung waren die Korinther bereits erfolgreich über ihren vorchristlichen Schatten gesprungen. In den genannten anderen Hinsichten hingegen waren sie noch längst nicht aus diesem

\footnotetext{
55 Wir könnten auch sagen: Die Korinther trennten nicht klar genug zwischen dem Verhalten in der christlichen Hausgemeinde und dem (umwelt-normierten) Verhalten im privaten Oikos, während Paulus die Grenzlinie zwischen beiden Sphären betont. Cf. so S. C. Barton, Paul's Sense of Place. An Anthropological Approach to Community Formation in Corinth, NTS 32, 1986, 225-246.
} 
Schatten herausgetreten; ihr in primae und secundae mensae zerfallendes Abendprogramm war dazu angetan, soziale Gegensätze mehr herauszukehren als zu überbrücken.

Das Problem der Prolongation vorbaptismalen Verhaltens im christlichen Kontext läßt sich auch sonst im 1 Kor beobachten ${ }^{56}$ : Nicht nur liebten die Griechen das Prozessieren, auch der Gang zur Hetäre war kulturell akzeptiert und normal (1Kor 6). Die Korintherinnen, die keinen Schleier trugen $(11,1 \mathrm{ff}$.$) , taten dies in einer Umwelt, in der es den Frauen völlig$ freistand, sich zu verschleiern, wie die bildlichen Darstellungen aus Italien und Griechenland belegen ${ }^{57}$; nur der vom Osten kommende Paulus war vom südöstlichen Kleinasien, von Syrien und Arabien anderes gewöhnt ${ }^{58}$. Das Essen von Götzenopferfleisch (1Kor 8-10) galt als problemlos; nur das Judentum schloß sich dieser gemeinantiken Ansicht nicht an. Die korinthische Orientierung am erhöhten, siegreichen Herrn (4,8 u. ö.) mag in der Heroenverehrung der Umwelt (bes. Herakles) eine Wurzel gehabt haben; das per aspera ad astra der Heroen hieß für die Korinther, daß Christus das Kreuz überwunden und hinter sich gelassen hat. Die korinthischen Apostel-Parteien $(1,12)$ fanden in der engen Verbindung zwischen Mystagoge und Neophyt eine Umweltparallele. Kurz, nicht alle korinthischen Regungen entsprangen einlinig einer bestimmten theologischen Haltung. Oft wurde schlicht nur altes, vorbaptismales Verhalten nach der Taufe weitergeführt.

Einem möglichen Einwand gegen unsere Rekonstruktion sei noch vorgebeugt. Die früh kommenden Korinther konnten - wie wir es darstellten - ihr »Voressen « in Analogie zu den primae mensae verstehen, das Sakrament des Herrenmahls dagegen in Analogie zu den secundae mensae. Befremdet ein solches Nacheinander von alltäglichem Essen und sakramentalem Handeln? Oder lassen sich Analogien für eine solche Abstufung nah beieinander liegender Akte beibringen? Abgesehen davon, daß wohl jede Rekonstruktion der korinthischen Szene mit diesem abgestuften Nacheinander zu rechnen hat, lassen sich Umweltanalogien finden. a) Wir sahen, daß beim paganen nicht-

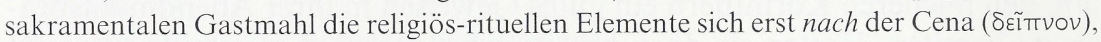
also nach den primae mensae, häuften: Bereits beim paganen Gastmahl bestand die Tendenz, den secundae mensae mehr religiöses Zeremoniell beizugeben als den primae. b) Darüber hinaus lassen sich Analogien in den Mysterienkulten finden. Die religionsgeschichtliche Kategorie, die zu vergleichen wäre, ist die des geselligen Sattessens als

56 Hierauf hat mit Recht J. Becker (Paulus. Der Apostel der Völker, Tübingen 1989, 211 - 213) hingewiesen. Dort die Beispiele, die freilich nicht 1Kor 11,17-34 einbeziehen.

57 Das Material präsentiert C. L. Thompson, Hairstyles, Head-coverings, and St. Paul. Portraits from Roman Corinth, BA 51, 1988, 99-115.

58 Cf. Dio Chrys., Orat 33,48, d. h. die 1. tarsische Rede: In der Öffentlichkeit verhüllen die tarsischen Frauen ihr Gesicht. Dgl. für Arabien Tert., VirgVel 17; für Palmyra und Dura Europos die archäologischen Zeugnisse bei Thompson, Hairstyles, 113. 
ritueller Begleithandlung ohne sakramentalen Charakter ${ }^{59}$. Der sakramentale Akt der Initiation wurde zuweilen von nicht-sakramentalen geselligen Mahlzeiten begleitet: Am Morgen unmittelbar im Anschluß an die Einweihungsriten in die Isismysterien gab es »einen lieblichen Schmaus und ein heiteres Gelage« (Apuleius, Met 11,24,1.5: Mane factum est et perfectis sollemnibus ... suaves epulae et faceta convivia). Plutarch und

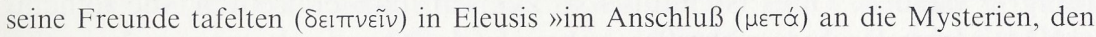
Höhepunkt des Festes«, im Privathaus eines Rhetors auf höchst gesellige Weise (Plut., QuConv 2,2 [635 AB]). Zu nennen ist vielleicht auch die Cena, die der Initiation in die Dionysosmysterien des Jahres 187 v. Chr. vorausging: Der in die Dionysosmysterien Einzuweihende übte zehn Tage lang Enthaltsamkeit, am zehnten Tag aß er, daraufhin reinigte er sich und wurde erst dann ins Heiligtum zur Weihe geführt (Liv. 39,9,4: decimo die cenatum, deinde pure lautum in sacrarium deducturam $)^{60} . \mathrm{Zu}$ nennen wäre auch die bekannte Stelle Jos., Ant 18,73f.: Die auf den Leim des Betrugs gehende ehrbare Römerin Paulina genoß im Isistempel zunächst ein nicht-sakramentales abend-

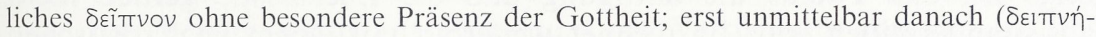
$\sigma \propto \sigma \propto)$ kam es zum »sakramentalen « Akt, nämlich zur - wie sie meinte - umarmenden Gemeinschaft mit Gott Anubis. c) Fraglich ist ferner, ob für alle geselligen Mahlzeiten in Tempelrestaurants, die sich an kultische Opferzeremonien im Tempel anschlossen, eine besondere Präsenz der Gottheit angenommen wurde. Ein Beispiel genüge (Plut., SeptSapConv 2,146 D): Periander lud seine Gäste zum Dinner in den Speisesaal neben dem Aphroditeheiligtum beim korinthischen Hafen Lechaeum ein. Er brachte der Göttin ein Opfer dar (146 D; 149 C) - offensichtlich noch bevor die anderen Gäste eintrafen. Abgesehen von diesem Opfer hätte sich Perianders Gastmahl für die sieben Weisen auch

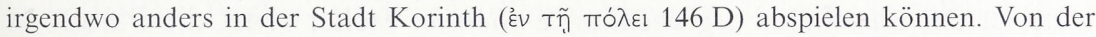
Vorstellung einer besonderen Präsenz der Aphrodite beim Mahl ist nichts zu spüren.

Fazit: Ein unmittelbares Nacheinander von alltäglichem Essen und kultischem Handeln bereitet keine Schwierigkeit.

\section{Paulus' praktische Empfehlungen}

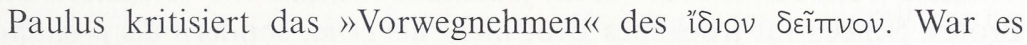
Heidenchristen möglich, zwischen primae und secundae mensae zu unterscheiden, so gibt es für Paulus, der das jüdische Festmahl (cf. Anm. 3) und die eucharistische Paradosis vor Augen hat, nur den Dreischritt Brotwort - Mahl - Kelchwort. Paulus stellt gegenüber den Korinthern klar, daß erst nach dem Brotwort das sättigende $\delta \varepsilon \tilde{T}$ vov stattzufinden

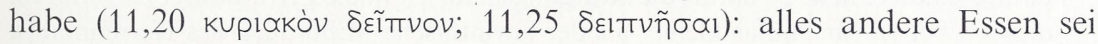

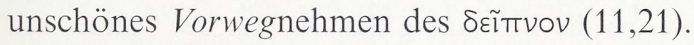

59 Cf. zu dieser Kategorie z. B. Klauck, Herrenmahl (s. Anm. 2) 131.

60 Nichts zeigt an, daß dieser Cena vor dem Initiationsritus ein besonderer sakramentaler Charakter eignete; die rituelle Reinigung, die die Initiation vorbereitete, kam erst nach dem Essen. Im allgemeinen präsentierten sich die Mahlzeiten in den Dionysosmysterien als »merely great banquets with a little thrill of religious ceremonies added « (M.P. Nilsson, The Dionysiac Mysteries of the Hellenistic and Roman Age, Lund 1957, 74). 


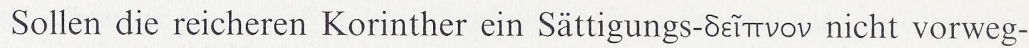
nehmen $(11,21)$, so ist zu folgern, daß Paulus nach dem Brotwort ein richtiges Sättigungsmahl stattinden lassen will - und nicht nur ein Austeilen von bloß Brot und Wein, bei dem womöglich wieder etliche hungrig bleiben. Oder ist Paulus so zynisch, daß er Leuten, die daheim $(11,34)$ nichts Rechtes zu beißen haben, in der Gemeindeversammlung nur Brot und Wein vorsetzt, während die Reichen daheim sich den Bauch mit Köstlichkeiten vollschlagen sollen (11,22a.34)? Auf solchen Zynismus liefe

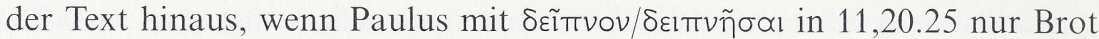
und Wein und nicht ein vollständiges Sättigungsmahl mit ö $\%$ ov meinte.

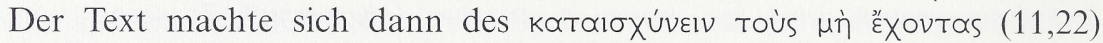
schuldig und kehrte sich so gegen sich selber. Aber tut er das? 11,33 zeigt an, daß Paulus die Sättigung und die Eucharistie gerade nicht auseinanderreißen will: Er rechnet weiterhin mit einem eucharistischen

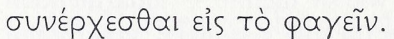

Anders votiert Theißen ${ }^{61}$ : Paulus zufolge sollen beim Herrenmahl nur Brot und Wein genossen werden. Die dem Paulus heilige Paradosis $(11,23-25)$ rede von keiner anderen Speise. Auch deute der Imperativ, »wenn jemanden hungert, soll er daheim essen « $(11,34$; cf. 11,22), in dieselbe Richtung: Nur daheim solle Zukost (öyov) wie Fisch, Gemüse oder Fleisch gegessen werden. Aber beide Gründe zwingen nicht. a) Der erste ist ein unsicheres argumentum e silentio. Sicher redet die Paradosis nur vom Brot. Aber Brot ist die Grundlage jedes Deipnons. Das ő also Fisch, Fleisch und anderes, wird gerade zum Brot gegessen ${ }^{62}$. Wer das Brot segnet, segnet deshalb die ganze Mahlzeit ${ }^{63}$. Die Möglichkeit besteht mithin durchaus, daß das ö wov auch für Paulus zum eucharistischen $\delta \varepsilon \tilde{T}$ vov dazugehört. In der Umwelt bezeichnet die von Paulus

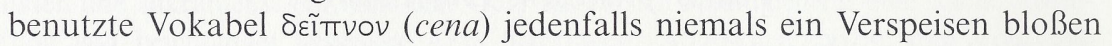
Brotes. Seneca ißt trockenes Brot nicht als cena, sondern als prandium in der Mittagshitze und braucht sich deshalb hinterher nicht die Hände zu waschen (Sen., Ep 83,6). Aber dies ist nicht einmal fürs prandium typisch

61 Integration (s. Anm. 4) 191 f. Ähnlich Klauck, Herrenmahl (s. Anm. 2) 294.371: Paulus plädiere in V. 22 dafür, die Sättigungsmahlzeit in die Privathäuser zu verlegen; dieses Übel sei für Paulus kleiner als der korinthische Mißbrauch des Herrenmahls; Paulus gehe es in erster Linie um die Bewahrung der Dignität des Sakraments. Ähnlich 324: Die heilige Speise fordert eine Aussonderung; mit ihr darf nur im Bewußtsein ihrer Heiligkeit umgegangen werden. Aber geht es Paulus primär um die Dignität der eucharistischen Elemente? S. u. Teil III.

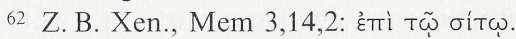

63 So auch für das jüdische Verständnis. Mischna Berakhot $6,5 \mathrm{C}$ : Wer das Brot segnet, segnet zugleich die Nebengerichte; cf. auch 6,7 B. Bes. 6,4: Bei mehreren gleichzeitigen Speisen genügt der Segen über einer derselben. Dazu T. Zahavy, The Mishnaic Law of Blessings and Prayers, Tractate Berakhot, Brown Judaic Studies $88,1987,84 \mathrm{f}$. 
(Plaut., Men $208 \mathrm{ff}$.). Bereits die Vorspeise der cena schließt Eier und Gemüse ein (Mart. 11,52; 12,19; 13,14), ganz zu schweigen von den anderen Gängen (11,31). Selbst die Sklaven des Begräbnisvereins von Diana und Antinous im italischen Lanuvium des Jahres 136 n. Chr. genießen außer Wein und Brot zumindest auch Fisch zur Cena ${ }^{64}$. Fisch gilt als ö $\psi$ ov par excellence ${ }^{65}$. b) 1 Kor 11,34 ist durchaus anders deutbar, als Theißen will. Die Aufforderung, bei Hunger daheim zu essen $(11,34)$, folgt unmittelbar auf die Mahnung, in der Versammlung mit dem Essen aufeinander zu warten $(11,33)$. Wegen der Kontextnähe ist das eine im Licht des anderen zu interpretieren: Die Korinther sollen mit dem sättigenden Deipnon aufeinander warten $(11,33$; cf. 11,21a). Und fällt dieses Warten einigen schwer, weil der Hunger (nach dem Bade) plagt (11,34a), dann soll schon zu Hause etwas verzehrt werden $(11,34 b=11,22 a)$. Dann wird das Warten nicht zur Plage und die Versuchung geringer, in der Versammlung schon vor der Ankunft der anderen das eigene Mitgebrachte auszupacken (11,21a).

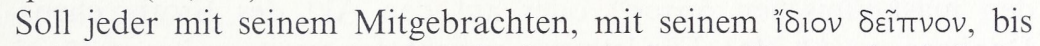
zur Ankunft aller warten $(11,21.33)$, dann bedeutet dies auch, daß das Mitgebrachte für alle zugänglich gemacht werden soll. Andernfalls hätte das Warten keinen Sinn, das offensichtlich ein Hungern der Habenichtse und ein kataıðXúveıv derselben $(11,21 \mathrm{f}$.) verhindern soll. In der Quintessenz laufen Paulus' praktische Empfehlungen so auf dasselbe hinaus wie die von Xenophon genannten sokratischen Maßnahmen: Rechten Gemeinschaftscharakter erhält ein Eranos, zu dem jeder nach Vermögen etwas mitbringt, erst dann, wenn das Mitgebrachte auch zum Mitgeteilten wird. Mitgeteilt kann aber nur werden, was a) nicht vorher schon weitgehend aufgegessen wurde und was b) entweder auf für alle zugänglichen Platten ausgebreitet wird oder vom Gastgeber auf die Teller aller verteilt

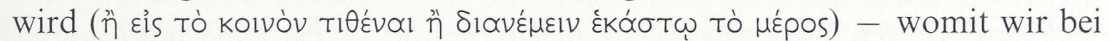
den Maßnahmen anlangen, die Sokrates dem beim Eranos servierenden Sklaven auftrug. Bedingung a) wird von Paulus in 1Kor 11,21.33 ausdrücklich genannt. Bedingung b) ist stillschweigend impliziert, wenn anders das

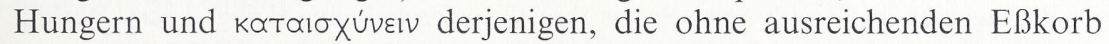
zur Versammlung erscheinen, verhindert werden sollen. Daß Bedingung b) nicht mehr expressis verbis ausgeführt wird, sagt Paulus selber: »Das Weitere werde ich bei meiner Ankunft ordnen « $(11,34)$. Der Logik des Textes folgend muß dieses "Weitere« in organisatorischen Anordnungen bestehen, die denjenigen des Sokrates für den Serviersklaven entsprechen. Paulus wird sie wie Sokrates in persona durchsetzen, falls die Korinther nicht schon selber diese Details geregelt haben werden ${ }^{66}$.

\footnotetext{
64 ILS 7212 Col. 2,14f.; cf. Col. 2,3.7.

65 Athen., Deipn 7,276 E-F.281-330; cf. Mk 6,41.

${ }^{66}$ Für letzteres stehen die Chancen gut (s. o. Anm. 42), so daß Paulus die Bedingung b) nicht extra ausformulieren muß.
} 


\section{Paulus' kreuzestheologische Grundlegung der praktischen Empfehlungen}

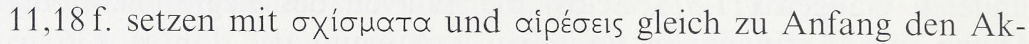
zent: Es geht Paulus um die Gemeinde, um intakte Gemeinschaft ${ }^{67}$. Das paulinische Betonen des Gemeinschaftscharakters des Mahles ist in der Umwelt nicht neu ${ }^{68}$. Neu ist die theologische Fundamentierung. Am Anfang der theologischen Argumentation steht die Paradosis 11,23-25; sie wird von Paulus redaktionell in 11,26 zusammengefaßt: Im Herrenmahl wird der Tod des Herrn verkündet.

1. Werfen wir zunächst einen kurzen Blick auf die Paradosis. Ohne Zweifel stellen sich Paulus und die Korinther eine Realpräsenz des Kyrios beim Mahl vor; der Kyrios nimmt als Gastgeber am Mahl teil (»prinzipale Realpräsenz«, s. Anm. 49). Ob darüber hinaus wie in Joh 6,51 ff. eine Realpräsenz in den Elementen vorgestellt wird, ist dagegen längst nicht klar: Das erste тoũto im Brotwort $(1$ Kor 11,24$)$ bezieht sich entweder auf den maskulinischen äp os $^{69}$ oder auf den Akt des Brotbrechens und Danksagens (11,24a). Für letzteres spricht das zweite toũto in 11,24, das

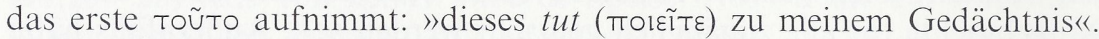
Durch diese Formulierung scheint das erste toũto als Akt qualifiziert: Der Akt des Danksagens und Brotbrechens wird gedeutet, nicht das Brot selber. Der Akt des Brotbrechens weist ${ }^{70}$ auf »den Leib (gebrochen) für euch«, mithin auf den Kreuzesleib und -tod Jesu ${ }^{71}$.

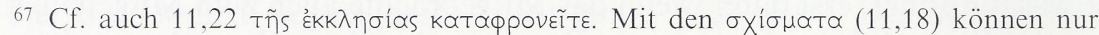
die genannten Unstimmigkeiten bei der Mahlgemeinschaft gemeint sein. Eine terminologische Parallele findet sich in den Statuten der ägyptischen Gilde des Zeus Hypsistos (1. Jh. v. Chr.; Text bei C. Roberts/T. C. Skeat/A. D. Nock, The Gild of Zeus Hypsistos, HThR 29, 1936, 39-88), Zeile 13: In der Gruppe sollen keine $\sigma x^{i \sigma \mu \alpha t \propto}$ auftreten, d.h. nichts, was die Mahlgemeinschaft trüben könnte, z. B. weder Streit noch Anklagen (Zeilen 15-18).

68 Einige pagane Beispiele mögen genügen. Parallel zu 1Kor 10,17 drückt sich für die Pythagoreer im Genuß eines Brotes ihre Gemeinschaft aus (Diog. Laert., VitPhil 8,35; Jambl., VitPyth 86). Plutarch, QuConv 614 D-615 A: Weil alle ein und denselben Wein trinken, sollen auch alle an ein und demselben Gespräch teilnehmen (614 E); d.h., die Diskussionsthemen dürfen nicht zu schwer sein. Cf. auch ebd.

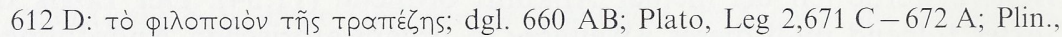
Ep 2,6; oben bereits Plut., QuConv 642 F-644 D; zu den Epikureern z. B. Smith, Obligation (s. Anm. 6) 56-67.

${ }^{69}$ Dies ist grammatisch immerhin möglich. Obwohl toũTo Neutrum ist, kann es sich auf ein Maskulinum beziehen: Das Neutrum rührt von der grammatikalisch geforderten Kongruenz eines Subjekt-Pronomens mit dem Prädikatsnomen (Tò $\sigma \tilde{\omega} \mu \alpha)$ her. Cf. z. B. Mt 7,12; 22,38; Act 16,12; Phil 1,28; Eph 3,13.

${ }^{70}$ Für घ̇๐тív = »bedeutet $«$ in allegorischen Gleichungen cf. z. B. Gal 4,24; Mk 4,15f.18.

71 Belege für $\sigma \tilde{\omega} \mu \alpha=»$ Mensch, der das Sterben erleidet«, bei E. Schweizer, Art. $\sigma \tilde{\omega} \mu \alpha$, ThWNT 7, 1964, 1025f.1043.1045.1055f. 
Mk 14,22 darf nach allem nicht zu schnell in 1Kor 11,24 hineingelesen werden.

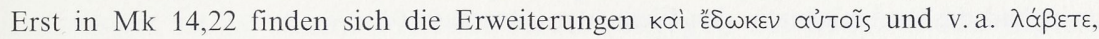

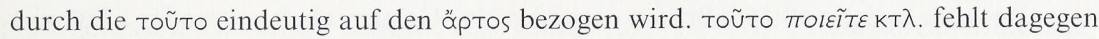
bei Mk bezeichnenderweise.

Werden bei Markus nicht die liturgischen Akte, sondern die Elemente gedeutet, so ist freilich auch so noch nicht zwingend eine Realpräsenz in den Elementen ausgesagt: દ’otiv in Mk 14,22 kann weiterhin wie in Mk 4,15 f.18 schlicht als »bedeutet« (s. Anm. 70) übersetzt werden.

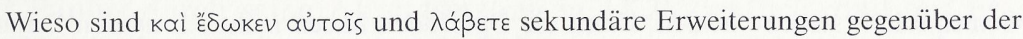
paulinischen Version? Insofern sie sicherstellen, daß das Element des Brotes auf den Leib zu deuten ist wie der Kelch auf das Blut, stehen sie deutlich im Dienste der liturgischen Parallelisierung von Brot- und Kelchwort; in Justin, Apol 66,3 (тоũTó દ́ఠтl Tò đĩúd nov) gelangt diese Parallelisierungstendenz zu ihrem Ende. Die paulinische Paradosis präsentiert sich dagegen noch völlig unsymmetrisch - egal wie das Brotwort in 1Kor 11,24 gedeutet wird: Der Kelch wird nicht auf das Blut, sondern auf den Bund gedeutet. Dieser Asymmetrie entspricht die zweifellos ältere liturgische Situation, daß Brot- und Kelchwort noch nicht zusammen rezitiert werden, sondern durch eine Mahlzeit getrennt sind (1Kor 11,25).

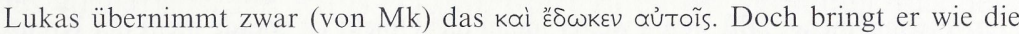
paulinische Paradosis und gegen Mk das тои̃тo тогєітє кт $\lambda$. und redet - wie Paulus

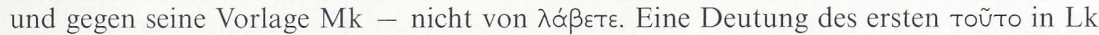
22,19 nicht auf das Brot, sondern auf den Akt bleibt so m. E. die bessere Möglichkeit: Jesus »nahm Brot, dankte, brach, gab ihnen und sagte: Dies (nämlich das Danken, Brechen und Austeilen des Brotes) weist auf meinen Leib, der im Begriff steht, für euch (am Kreuz) dahingegeben zu werden ${ }^{72}$; dies (nämlich das Danken, Brechen und Austeilen des Brotes) tut zu meiner Anamnesis. « Die miteinander korrespondierenden है $\delta \omega \kappa \varepsilon v$ und $\delta ı \delta$ $\mu \varepsilon v o v$ erhöhen geradezu die Konzentration auf den Akt - und nicht auf das Element.

Beim Kelchwort von 1Kor 11,25 bietet sich eine ähnliche Struktur wie beim Brotwort 1Kor 11,24. Der Kelch weist nicht auf das Blut Christi, sondern auf »den neuen Bund «, der aufgrund des am Kreuz vergossenen Blutes gestiftet wurde. Da nicht auf das Blut selber gedeutet wird, läßt sich auch aufgrund des Kelchworts keine sakramentale Präsenz des Kyrios im Element behaupten.

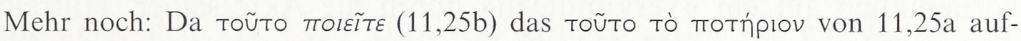
nimmt, könnte тотńpıov weniger für das Element des Weins als vielmehr wieder für den $A k t$ des segnenden $(10,16)$ Danksagens über dem Kelch und des gemeinsamen Trinkens aus ein und demselben Kelch stehen. Dieser Gemeinschaft ausdrückende $A k t$ wiese dann auf den Neuen Bund hin.

Repräsentiert die vorpaulinische Paradosis 1Kor 11,23-25 kaum die Vorstellung einer Realpräsenz in den Elementen, so bleibt zu fragen, ob nicht Paulus und die Korinther einen Schritt weiter waren ${ }^{73}$. In 10,16;11,27 werden anders als in der Paradosis

72 Das Partizip Praesens weist auf eine nachfolgende Handlung und steht wie Act 21,2 f. für o̊ $\mu \dot{\varepsilon} \lambda \lambda \varepsilon \varepsilon$ + Infinitiv. Cf. Bl.-D. §339,2.

73 So z. B. Klauck, Herrenmahl (s. Anm. 2) 312. Er vermutet, Paulus habe die Realpräsenz in den Elementen vertreten (374). 
Kelch/Blut und Brot/Leib bereits parallelisiert. Doch ist damit wiederum noch nicht zwingend die Realpräsenz in den Elementen ausgesagt:

koıvcuvía tıvós in 10,16 läßt sich entweder als »Gemeinschaft mit « oder »Teilhabe am« Leib und Blut des Herrn interpretieren. Die alte Debatte soll nicht aufgerollt werden. Entscheidend für die Interpretation ist m. E. der Begriff kolvwvoí tıvos in 10,18.20. Ist 10,18 noch für beide Bedeutungen offen (»Personen, die mit dem Altar in Gemeinschaft stehen«, oder »Personen, die an dem Altar [bzw. seinen Opfern] teilhaben «), so wird 10,20 eindeutig: Hier kann es nur »Leute, die mit den Dämonen in Gemeinschaft stehen« heißen. Denn die Opfernden haben nicht teil an den Dämonen, sondern sie haben mit den Dämonen zusammen an den Opfern teil, was zur Gemeinschaft mit den Dämonen führt. Entsprechend werden 10,16 zufolge die Eucharistieteilnehmer in die Gemeinschaft mit dem Todesleib Christi gestellt. So bleibt die Möglichkeit, daß 10,16 von der Gemeinschaft mit dem Todesleib Christi in dem Sinne redet, daß die Christen im Sakrament am Todesschicksal Christi teilnehmen (Röm 6; 7,4): Sie sterben mit Christus mit.

$\mathrm{Ob}$ die Christen darüber hinaus diesen Kreuzesleib auch noch in den Elementen essen (cf. Joh 6,52 ff.) und so mit ihm in kolvwvía treten, ist dagegen durchaus nicht

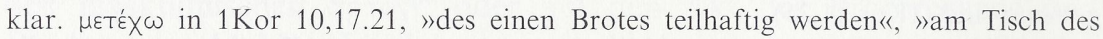
Herrn teilnehmen«, hilft wenig weiter, denn das Objekt ist gerade nicht der Kreuzesleib, sondern das Element des Brotes. Dieses Element wird in 10,16 zwar mit dem Kreuzesleib parallelisiert, doch stellt sich - wie bei der markinischen Abendmahlstradition - die Frage, ob es dadurch mit dem Kreuzesleib identifiziert wird; 10,16 lautet gerade nicht: »Das Brot, das wir brechen, ist das nicht der Kreuzesleib Christi? «

Auch in 10,4 ist der pneumatische Trank der Eucharistie nicht mit Christus identisch, sondern er kommt von Christus her und stiftet so Gemeinschaft mit ihm. Das Modell des real präsenten Gastgeber-Christus paßt auch für 10,4 viel besser als das der Realpräsenz in den Elementen.

2. Wichtig ist an dieser Stelle, wie Paulus in 11,26 die Paradosis von 11,23-25 zusammenfaßt und für seinen Argumentationsgang fruchtbar macht. Das Essen des Brotes und das Trinken aus dem Kelch, beide sakramentalen Akte vergegenwärtigen (jeder für sich) den Kreuzestod Jesu: Beide Akte »verkündigen" $(11,26)$ den Tod Christi. Mögen Worte beim Herrenmahl dieselbe Funktion wahrnehmen, Vers 26 lenkt den Blick vornehmlich auf ein »Verkündigen« durch die Akte selber. Hilfreich ist die von Klauck vorgeschlagene Kategorie der »kommemorativen Aktualpräsenz«: Durch die darstellenden sakramentalen Akte, durch den mittels der Akte und Worte erinnernden Rückblick wird Christi Kreuzestod »aktualiter gegenwärtig « ${ }^{74}$.

Faßt Paulus die Paradosis im Sinne der »kommemorativen Aktualpräsenz« des Kreuzestodes bzw. des Gekreuzigten zusammen und nicht im Sinne der »prinzipalen Realpräsenz« des Erhöhten als Gastgebers, so liegt bereits darin ein Stück Kritik am korinthischen Enthusiasmus

74 A. a. O., $373 \mathrm{f}$. Vergegenwärtigung des göttlichen Schicksals kennen auch die Mysterienkulte. Doch hegen diese ein anderes Zeitverständnis; dazu Klauck 368.371. 
beschlossen, der an eben der »prinzipalen Realpräsenz« des Erhöhten interessiert ist (s. Anm. 49), das Kreuz dagegen als überwunden hinter sich gelassen zu haben scheint (cf. 1Kor 4,8). Paulus' Akzentverschiebung von der »prinzipalen Realpräsenz« des erhöhten Kyrios auf die »kommemorative Realpräsenz« des Kreuzestodes bedeutet sicher nicht, daß für den Apostel erstere nicht existierte; kaum können beide Arten der Realpräsenz auseinandergerissen oder gar gegeneinander ausgespielt werden. Doch macht Paulus durch seine Akzentsetzung in 11,26 deutlich, daß der Erhöhte für die Christen immer nur als Gekreuzigter zu erfahren ist, solange der eschatologische Vorbehalt gilt $(11,26$ fin). Bereits das Perfekt દ̇øtavp๘uḱvov von 1 Kor 2,2 vermittelte diesen Gedanken: Wird Christus verkündet, so nur als jemand, dessen Kreuzestod nicht nur (aoristisch) vergangen ist, sondern (perfektisch) die Gegenwart qualifiziert. Ging es in 2,2 um die Verkündigung dieses Gekreuzigten im Wort, so in 11,26 um die Verkündigung und Vergegenwärtigung im sakramentalen Akt.

3. Die Vergegenwärtigung des Todes Christi, für Paulus die Quintessenz des eucharistischen Ritus $(11,26)$, führt zu einem Verhalten, das den Hungernden an der Seite nicht vernachlässigt $(11,22)$. Wie kommt Paulus zu diesem überraschenden Brückenschlag zwischen Sakrament und Ethos? Oder anders: Wie ist das $̋ \circ \tau \varepsilon$ in 11,27 zu begreifen? Was haben 11,2325 , zusammengefaßt in 11,26 , mit dem Rest des Textes zu tun? Was hat das Verkündigen des Todes Christi im Herrenmahl mit dem von den Korinthern geforderten praktischen Verhalten beim Mahl zu tun? Hier liegt die zentrale Frage des Textes ${ }^{75}$. Paulus führt den Brückenschlag zwischen Sakrament und Ethos nicht aus. Für den Nachvollzug des Brückenschlags sind wir auf paulinische Paralleltexte angewiesen. a) Vergegenwärtigung des Heilstodes bedeutet zunächst, daß das von diesem Tod

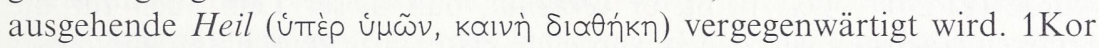
8,11: Christus starb auch für die Schwachen, was als ethische Konsequenz einschließt, daß der Starke den Schwachen nicht zugrunderichten darf. Analog ließe sich für Kap. 11 formulieren: In der Eucharistie wird das am Kreuz gestiftete Heil vergegenwärtigt, das nicht nur den Reicheren, sondern auch den Ärmeren gilt. Wie können dann die Reicheren die Ärmeren demütigen (cf. 11,22)? Wer die Ärmeren und Schwächeren zugrunderichtet, für die Christus auch gestorben ist, sündigt gegen Christus $(8,12)$. 11,27 formuliert parallel, daß er sich am Tod Jesu mitschuldig macht. Hier wäre ein erster Brückenschlag. Auch noch zwei andere sind möglich. b) Vergegenwärtigung des Heilstodes heißt, daß der Tod Christi am Kreuz präsent wird. Nach Phil 2 ist dieser Tod der Inbegriff der

75 So schon J. Weiss, Das Urchristentum, Göttingen 1917, 510: Es wird nicht klar, »inwiefern die Berufung auf die Herrenworte und die Erklärung des Sinnes der Feier dazu dienen soll, die korinthische Unsitte zu bekämpfen. In dieser Frage liegt das eigentliche Problem der Stelle.« 
liebenden Selbstentäußerung Christi. In der Eucharistie wird diese Selbstentäußerung vergegenwärtigt. Wie können Eucharistieteilnehmer dann noch egozentrisch an den Nöten der Nächsten achtlos vorbeischauen? Die Selbstentäußerung des Kyrios zum Wohle anderer drängt die Christen zu einer ebensolchen (Phil 2,4f.). c) Sakramentale Vergegenwärtigung des Kreuzestodes Christi bedeutet nach Röm 6,2-8, daß die Christen im Sakrament mit Christus mitsterben. Das Sakrament gibt nicht nur Anteil an dem vom Kreuzestod ausgehenden Heil, es gibt auch Anteil an diesem Tod selber. Röm 6 formuliert dies im Blick auf die Taufe. Aber auch im Blick auf die Eucharistie gilt diese Art der Vergegenwärtigung. 1Kor 10,16f. zufolge bedeutet das Herrenmahl, wie wir sahen, eine Gemeinschaft (kolvwvia) mit dem Kreuzesleib, das heißt, mit dem Todesleiden Christi. Für Paulus bedeutet diese Gemeinschaft, daß er in seinem eigenen Leben Christi Tod repräsentiert: Er trägt Christi Leiden an seinem Leib herum (2Kor 4,7-12, bes. 4,10f.). Eine solche Kreuzesexistenz - ein Leben, das dem Kreuzesleiden Christi entspricht - schließt das Absehen vom eigenen Ich und den Einsatz für andere ein (1Kor 4,11-13 u. ö.), womit wir wieder bei demselben Ethos anlangen.

Es ist offensichtlich, daß diese drei Brückenschläge zwischen Sakrament und Ethos sich nicht ausschließen, sondern sich überschneiden. Allen dreien ist gemeinsam, daß das Vergegenwärtigen und Applizieren des Heilstodes Christi auf die Christen mit einem den Nächsten zugewandten Verhalten einhergeht, wenn anders die Christen nicht am im Sakrament vergegenwärtigten Tod Christi mitschuldig werden wollen $(11,27)^{76}$.

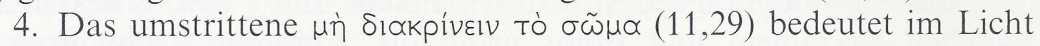
dieser drei Brückenschläge: Wer an den Nächsten lieblos vorbeilebt, »schätzt den Kreuzesleib Christi nicht richtig ein«, der für uns gebrochen wurde $(11,24)^{77}$. Das heißt, er verkennt, daß dieser Leib auch für die ärmeren Nächsten gebrochen wurde (= erster Brückenschlag), daß dieser Kreuzesleib eine Selbstentäußerung Christi bedeutet, die auf die Christen appliziert werden will (= zweiter Brückenschlag), und daß die Christen mit diesem Kreuzesleib Christi in eine enge Gemeinschaft treten: Sie sterben mit Christus mit; der Sünde abgestorben (Röm 6,11), werden sie frei, sich anderen zuzuwenden ( $=$ dritter Brückenschlag).

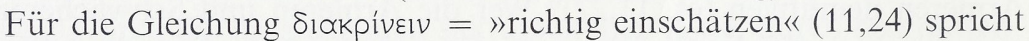
auch das reflexive Siakpíveıv in 11,31, das dieselbe Bedeutung trägt; es

76 Diese Verbindung von Sakrament und gemeinschaftsbezogener Ethik liegt auch 10,16 f. zugrunde: Die Gemeinschaft mit dem Todesleib und -leid Christi $(10,16)$ ist untrennbar von der Gemeinschaft der Christen untereinander $(10,17)$. Genuin gehört zum Sakrament nicht nur eine vertikale, die Gemeinschaft mit Christus befestigende Dimension, sondern ebenso eine horizontale, d.h. ethische und ekklesiologische Ebene.

77 Sıakpivw als »richtig einschätzen« z. B. in Mt 16,3 vom Himmel und von den Zeichen

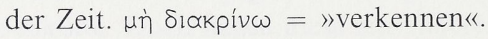


steht parallel zum reflexiven ठокциґц́ंт in 11,28. Die Eucharistieteilnehmer haben sich selber zu »prüfen « $(11,28)$, sie haben sich selber »richtig einzuschätzen « (11,31): Entspricht ihr Verhalten auf der zwischenmenschlichen Horizontalen dem, was Christus in seinem Tod für andere tat?

Entspricht das eigene Verhalten, baut es die Nächsten und die Ge-

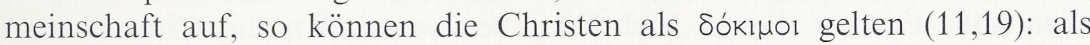
solche, die im eschatologischen Gericht bestehen ${ }^{78}$. Entspricht das Verhalten nicht, so wird das Sakrament »unwürdig« $(11,27)$ genossen, und die Christen werden zwar nicht im Eschaton mit der Welt verdammt werden (катакрivw; 11,32; cf. 5,5; 3,15), wohl aber schon jetzt vom Kyrios gerichtet (кpívw, kpíma), d.h. durch körperliche Schwäche, Krankheit und Tod gezüchtigt $(11,29-32)^{79}$.

Ist der schon jetzt richtende und züchtigende Kyrios $(11,32)$ zugleich der im Herrenmahl präsente, so bedeutet dies, daß seine sakramentale Realpräsenz nicht als etwas Verfügbares der Gemeinde ausgeliefert ist. Der göttliche Souverän wird auch im Sakrament nicht an den Menschen gebunden, wohl aber der Mensch und sein Verhalten im Sakrament von Gott in Beschlag genommen und der Herrschaft des Kyrios unterstellt.

Zusammenfassend läßt sich formulieren: Nur in der fürsorgenden Zuwendung zu den anderen handelt der Eucharistieteilnehmer dem Tod Christi gemäß, mit dem dieser sich für andere aufopferte. In dieser Zuwendung auf der zwischenmenschlichen Horizontalen verkündet der Eucharistieteilnehmer den Tod Christi als etwas heilsam für andere Geschehenes. Paulus interpretiert die Paradosis radikalisierend dahingehend, daß mit jedem Aspekt des Herrenmahls an den Heilstod Christi und an den durch

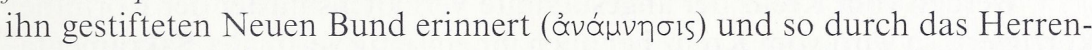
mahl dieser Tod verkündet und präsent wird. Mit anderen Worten: Die Verkündigung dieses Todes geschieht im Herrenmahl nicht nur durch

7811,19 ist am ehesten aufs Endgericht zu deuten. Spannungen und Spaltungen geben Gelegenheit, sich fürs jüngste Gericht zu bewähren (Act 20,30 f.; Mt 24,23 ff.; Just., Dial 35,3 u. ö.). In unserem Kontext besteht die Bewährung darin, angesichts des Zu-Kurz-Kommens etlicher Mitchristen und des dadurch angerichteten Schadens für die Gemeinschaft $(\sigma x i \sigma \mu \alpha \tau \alpha)$ ein aktives Liebesverhalten auf der zwischenmenschlichen Horizontalen an den Tag zu legen.

79 útrò kupíou in 11,32 schließt einen magischen Automatismus bei den Elementen aus: Die Elemente wirken nicht wie krankmachendes Gift, wenn sie unwürdig genossen werden. Vielmehr läßt der Kyrios krank werden. Sein kpíu๔/kpíveıv $(11,29.31$ b.32.34) ist nicht (wie Mt 25,31 ff.) futurisch-eschatologisch, sondern in diesem Falle proleptisch-präsentisch: Es bietet die Grundlage für das gegenwärtige Gezüchtigtwerden

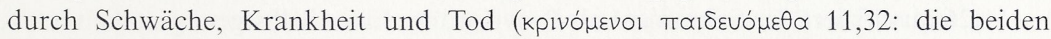
Handlungen laufen parallel; das Verhältnis ist kausal oder konditional). Im Judentum gilt solch vorwegnehmendes Richten und Züchtigen, das einem Todesurteil im Endgericht vorbeugt, als Gnade (Bill. 2, 277f.). 
die diesen Tod darstellenden liturgischen Akte des Brotbrechens und Weintrinkens, nicht nur durch die den Ritus begleitenden Dankes- und Segensworte. Sie geschieht während des Herrenmahles (und sonst im Alltag) vor allem auch durch das zwischenmenschliche Verhalten der Christen, das dem Sich-für-andere-Hingeben des Christustodes entsprechen soll. Erst in diesem Sich-Hingeben verkünden die Christen den Heilstod Christi recht: Erst so stellen sie den Tod Christi anderen Menschen konkret erlebbar dar, ihn repräsentierend und vergegenwärtigend.

Blicken wir auf die korinthische Szenerie zurück: Durch den Hinweis auf den Kreuzestod Christi korrigiert Paulus zwei Mahlpraxeis, die die Korinther aus ihrer Umwelt und paganen Vergangenheit mitgebracht haben. Paulus versucht erstens, die Sitte des Eranos, des Mitbringens eigener Speisen, dahingehend zu gestalten, daß sie auch ein Mitteilen wird. Paulus votiert hier wie der xenophonische Sokrates. Spezifisch christlich, ja paulinisch nimmt sich jedoch das Motivieren des gemeinschaftsfördernden

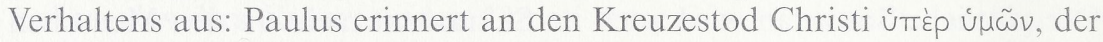
im Sakrament vergegenwärtigt und auf die Christen appliziert wird; ihm entsprechend haben die Christen zu leben. - Zweitens werden die reicheren Korinther aus ihrer unreflektierten Zweiteilung des Abends in primae und secundae mensae aufgerüttelt. Wer zu den secundae mensae erscheint, wird in der Umwelt nicht gefragt, ob er noch Hunger hat. So sättigen die reicheren Korinther sich ohne Gewissensbisse an, wie sie es vermutlich verstehen, primae mensae und kümmern sich nicht um die hungrigen Mägen derjenigen, die erst zu den secundae mensae erscheinen. Auch dieses Verhalten ist vom Kreuz her gesehen als lieblos zu kritisieren.

Werden vom Kreuz her angestammte Verhaltensmuster der Korinther korrigiert, so wird vom Kreuz her auch ihr einseitig vertikaler Sakramentalismus kritisiert: Die Korinther interessieren sich für die vertikale Gemeinschaft mit dem erhöhten Kyrios im Sakrament und übersehen die Nöte der Mitchristen auf der Horizontalen. Gemeinschaft mit dem Kyrios bedeutet für den Kreuzestheologen Paulus aber gerade Gemeinschaft mit Christi Kreuzestod; der Erhöhte ist, solange der eschatologische Vorbehalt gilt, nur als der Gekreuzigte zu erfahren $(2,2)$. Wer sich in die Gemeinschaft mit dem Gekreuzigten und seinen Leiden begibt, beginnt, auch dessen am Kreuz manifeste Liebe für andere zu teilen und wird zu einem aktiven Liebesverhalten auf der zwischenmenschlichen Horizontalen geführt.

Der Hinweis auf den Tod Christi zerschlägt den Korinthern schlußendlich jede falsche sakramentale Sicherheit ${ }^{80}$ : Die Realpräsenz des ge-

80 Cf. in dieser Funktion auch a) 10,1 ff. sowie b) 11,26 fin. Der Parusieausblick in 11,26 qualifiziert das Sakrament als Provisorium. Einer Selbstgenügsamkeit (cf. 4,8), die im Jetzt des Kultakts seine Erfüllung findet, wird der Riegel vorgeschoben. Die Christus-Präsenz in der Eucharistie, vom Gekreuzigt-Sein des Kyrios geprägt, hat eine andere Qualität als die Christus-Präsenz in der Parusie. 
kreuzigten und erhöhten Herrn im Sakrament wird dem Menschen nicht als etwas Verfügbares ausgeliefert; sie verpflichtet vielmehr den Menschen und sein Handeln. Die Christen werden im Sakrament entsprechend unter das kpíma des richtenden Kyrios gestellt (11,27-32). Der Kyrios erweist sich so auch in seiner Selbstbindung ans Sakrament als souveräner. 